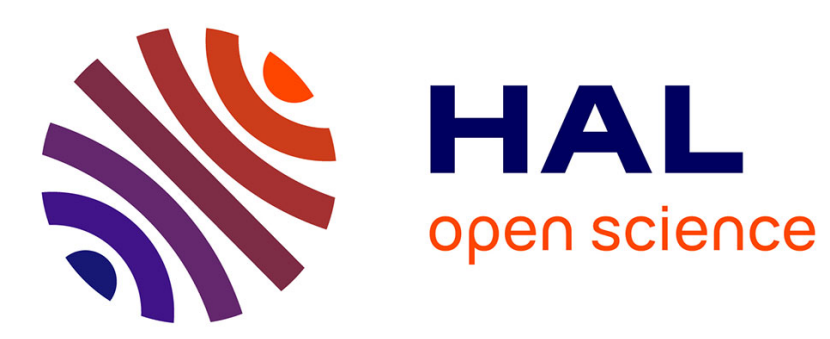

\title{
A global perspective on the sub-seasonal clustering of precipitation extremes
}

\author{
Alexandre Tuel, Olivia Martius
}

\section{To cite this version:}

Alexandre Tuel, Olivia Martius. A global perspective on the sub-seasonal clustering of precipitation extremes. Weather and Climate Extremes, 2021, 10.1016/j.wace.2021.100348 . hal-03359069

\section{HAL Id: hal-03359069 \\ https://hal.science/hal-03359069}

Submitted on 29 Sep 2021

HAL is a multi-disciplinary open access archive for the deposit and dissemination of scientific research documents, whether they are published or not. The documents may come from teaching and research institutions in France or abroad, or from public or private research centers.
L'archive ouverte pluridisciplinaire HAL, est destinée au dépôt et à la diffusion de documents scientifiques de niveau recherche, publiés ou non, émanant des établissements d'enseignement et de recherche français ou étrangers, des laboratoires publics ou privés. 


\title{
A global perspective on the sub-seasonal clustering of precipitation extremes
}

\author{
Alexandre Tuel ${ }^{\mathrm{a}, *}$, Olivia Martius ${ }^{\mathrm{a}, \mathrm{b}}$ \\ ${ }^{a}$ Institute of Geography and Oeschger Centre for Climate Change Research, University of Bern, Switzerland \\ ${ }^{\mathrm{b}}$ Mobiliar Lab for Natural Risks, University of Bern, Switzerland
}

\section{A R T I C L E I N F O}

$\overline{\text { Dataset link: https://apps.ecmwf.int/datasets/, }}$ https://disc.gsfc.nasa.gov/datasets/TRMM_3B4 2_Daily_7/summary

\section{Keywords:}

Precipitation extremes

Temporal clustering

Time series statistics

\begin{abstract}
A B S T R A C T
The occurrence of several precipitation extremes over sub-seasonal time windows can have major impacts on human societies, leading for instance to floods. Here, we apply a simple statistical framework based on Ripley's K function, at a global scale and for each season separately, to identify regions where precipitation extremes tend to cluster in time over timescales of a few days to a few weeks. We analyze several observational and reanalysis datasets, as well as output from CMIP6 Global Climate Models (GCMs). Good agreement is found on the spatio-temporal clustering patterns across datasets. Sub-seasonal temporal clustering is largely concentrated over the tropical oceans, where it can be detected year-round. It is also significant over certain tropical lands, like Eastern Africa, and seasonally outside the tropics in several regions, most notably around the eastern subtropical oceans (Iberian Peninsula and Western North America during the DJF and MAM seasons) Southwest Asia (especially during JJA and SON) and Australia (in SON). We also find that CMIP6 models generally correctly reproduce clustering patterns, paving the way for an assessment of trends in sub-seasonal clustering under climate change. Clustering of present-day extremes increases in many areas under climate change. Changes diagnosed by comparing present day and future extreme percentiles are positive and negative and strongest in the tropical areas.
\end{abstract}

\section{Introduction}

Precipitation extremes can have major impacts on humans and ecosystems, among which floods or landslides. Consequently, the characteristics of precipitation extremes (e.g., spatio-temporal distribution, trends, sensitivity to climate change) have been extensively analyzed in the literature (e.g., Westra et al., 2013; Sillmann et al., 2013; O'Gorman, 2015). The impact of precipitation extremes, however, can be much more severe if several events occur in close succession, in which case one talks of a compound event (Zscheischler et al., 2020). Short time intervals between heavy precipitation events can indeed complicate clean-up and repair efforts, as well as prevent hydrological systems from returning to base flow conditions. The temporal distribution of precipitation has a major impact on the flow response and flood characteristics (Merz et al., 2016; Oppel and Fischer, 2020). Successive extreme precipitation events can trigger a larger flow response, as in Pakistan in 2010 (Martius et al., 2013), in the UK during the 2013/2014 winter (Priestley et al., 2017b), or in Southern Switzerland in 2016 (Barton et al., 2016). Analyzing the tendency of precipitation extremes to cluster in time, typically on timescales of a few days to a few weeks that can be relevant for hydrology, is therefore crucial to robustly assess climate risks.
Sub-seasonal serial/temporal clustering of precipitation extremes and associated weather systems has already been the subject of several studies, most of them limited, however, to catchment or regional scales. Specific clustered events, often linked to high-impact flood events, and their large-scale atmospheric context have been the topic of many studies, for instance over Europe (Blackburn et al., 2008; Grams et al., 2014; Pinto et al., 2014; Barton et al., 2016; Priestley et al., 2017a,b), California (Moore et al., 2020) or Pakistan (Martius et al., 2013). Villarini et al. (2011) conducted a more systematic analysis of the clustering of extreme precipitation at the annual timescale over the American Midwest, using as a statistical metric the dispersion coefficient, the variance-to-mean ratio of annual extreme counts. Mailier et al. (2006), Vitolo et al. (2009) and Pinto et al. (2013) similarly relied on the dispersion coefficient to assess clustering of extratropical storms in the Euro-Atlantic sector during the winter half-year. Barton et al. (2016) used Ripley's $\mathrm{K}$ function to quantify temporal clustering and found significant clustering of heavy precipitation over Southern Switzerland during fall, and Yang and Villarini (2019) analyzed the effect of largescale climate modes on the temporal clustering of extreme precipitation over Europe. More recently, Kopp et al. (2021) quantified the frequency of sub-seasonal clustering of annual high-precipitation events

\footnotetext{
* Corresponding author.

E-mail address: alexandre.tuel@giub.unibe.ch (A. Tuel).
} 
and its contribution to large precipitation accumulations over land at the global scale using count-based metrics. Even fewer studies have attempted to quantify potential future trends in the temporal clustering of extreme precipitation. Focusing specifically on mid-latitude winter cyclones over Europe, Economou et al. (2015) found no significant changes in cyclone dispersion statistics whereas Pinto et al. (2013) and Bevacqua et al. (2020) both argued that future climate projections showed a decrease in the temporal clustering of cyclones in the region. Yet, to our knowledge, however, no study has looked at future trends in the temporal clustering of extreme precipitation at the global scale.

The studies cited previously vary in their spatial scope, in the clustering timescales they analyze, but also in their definition of what constitutes an extreme event. From the perspective of surface impacts, it can make sense to define precipitation extremes using annual percentiles, i.e. fixed percentile thresholds independent of the season (Villarini et al., 2011; Yang and Villarini, 2019; Kopp et al., 2021). Still, this choice has its limitations. First, severe surface impacts of extreme precipitation accumulations, like floods, do not always occur in conjunction with the heaviest precipitation totals (e.g., Helbling et al., 2006; Tuel and Martius, 2021). The phase of precipitation and surface conditions, like soil saturation, evaporative demand or vegetation, also matter (e.g., Berghuijs et al., 2019). Consequently, annual cycles of extreme precipitation and river discharge magnitude are not necessarily aligned. Second, in the case of a fixed annual percentile threshold, subseasonal clustering of extremes may simply result from seasonality in the occurrence of extreme precipitation.

By taking variable percentile thresholds using seasonal or monthly percentiles, as in Barton et al. (2016), the influence of the seasonality can be removed, and clustering at sub-seasonal timescales can be detected. Additionally, when considering the impact of clustering on flooding hazard, the choice of variable thresholds is quite flexible, in the absence of any a priori knowledge of relevant flood triggering processes. Depending on the location of interest, one can focus on the season when precipitation extremes are important for flood generation. Finally, most studies have focused only on a few specific regions, which may not be the most relevant ones when it comes to sub-seasonal clustering of precipitation extremes. Only Kopp et al. (2021) took a global perspective, but excluded tropical land areas from their analysis.

Here, we seek to answer the following questions: (1) Where and in what season(s) does extreme precipitation tend to cluster temporally at sub-seasonal timescales? (2) How and where does temporal clustering of extreme precipitation change in the future? To that end, we adopt the approach of Barton et al. (2016) by defining extreme precipitation events using seasonal percentiles, and using the framework of Ripley's $\mathrm{K}$ function to identify regions with significant sub-seasonal clustering of precipitation extremes in time. We investigate each season separately. The spatial and seasonal distribution of sub-seasonal clustering and its robustness, in the current and future climates, are discussed using several global observation- and model-based precipitation datasets.

\section{Data and methods}

As the reference dataset, we use daily precipitation at $0.25^{\circ}$ resolution from the ERA5 reanalysis (Hersbach et al., 2020). The data covers the whole world and extends over the 1979/1/1-2019/3/31 period. Precipitation in ERA5 is a prognostic variable and precipitation observations are not directly assimilated into the model. In the extratropics, Rivoire et al. (2021) showed that ERA5 was able to capture the timing of extreme precipitation events, but less so in the tropics. Therefore, we also use three other satellite-based daily precipitation products: TRMM TMPA (TRMM Multi-Satellite Precipitation Analysis) $3 \mathrm{~B} 42$ version $7\left(50^{\circ} \mathrm{S}-50^{\circ} \mathrm{N}, 1998-2019,0.25^{\circ}\right)$ (Huffman et al., 2007), CMORPH $\left(60^{\circ} \mathrm{S}-60^{\circ} \mathrm{N}, 2003-2019,0.25^{\circ}\right)$ (Joyce et al., 2004), and GPCP One-Degree Daily (1DD) version $1.2\left(40^{\circ} \mathrm{S}-40^{\circ} \mathrm{N}, 1997-2019\right.$, $1^{\circ}$ ) (Huffman et al., 2001), as well as the Climate Prediction Center Global Unified Gauge-Based Analysis of Daily Precipitation (global,
Table 1

List of CMIP6 models used in this study. Resolution is in longitude by latitude.

\begin{tabular}{ll}
\hline Name & Resolution \\
\hline ACCESS-CM2 & $1.9^{\circ} \times 1.3^{\circ}$ \\
ACCESS-ESM1-5 & $1.9^{\circ} \times 1.2^{\circ}$ \\
BCC-CSM2-MR & $1.1^{\circ} \times 1.1^{\circ}$ \\
CanESM5 & $2.8^{\circ} \times 2.8^{\circ}$ \\
CESM2-WACCM & $1.3^{\circ} \times 0.9^{\circ}$ \\
CNRM-CM6-1 & $1.4^{\circ} \times 1.4^{\circ}$ \\
EC-Earth3 & $0.7^{\circ} \times 0.7^{\circ}$ \\
EC-Earth3-Veg & $0.7^{\circ} \times 0.7^{\circ}$ \\
FGOALS-g3 & $2^{\circ} \times 2.3^{\circ}$ \\
GFDL-CM4 & $1.3^{\circ} \times 1^{\circ}$ \\
GFDL-ESM4 & $1.3^{\circ} \times 1^{\circ}$ \\
HadGEM3-GC31-MM & $0.8^{\circ} \times 0.6^{\circ}$ \\
IITM-ESM & $1.9^{\circ} \times 1.9^{\circ}$ \\
INM-CM4-8 & $2^{\circ} \times 1.5^{\circ}$ \\
INM-CM5-0 & $2^{\circ} \times 1.5^{\circ}$ \\
IPSL-CM6A-LR & $2.5^{\circ} \times 1.3^{\circ}$ \\
KIOST-ESM & $1.9^{\circ} \times 1.9^{\circ}$ \\
MIROC6 & $1.4^{\circ} \times 1.4^{\circ}$ \\
MPI-ESM1-2-LR & $1.9^{\circ} \times 1.9^{\circ}$ \\
MPI-ESM1-2-MR & $0.94^{\circ} \times 0.94^{\circ}$ \\
MRI-ESM2-0 & $1.1^{\circ} \times 1.1^{\circ}$ \\
NESM3 & $1.9^{\circ} \times 1.9^{\circ}$ \\
NorESM2-LM & $2.5^{\circ} \times 1.9^{\circ}$ \\
NorESM2-MM & $1.25^{\circ} \times 0.94^{\circ}$ \\
TaiESM1 & $1.25^{\circ} \times 0.94^{\circ}$ \\
\hline
\end{tabular}

land only, 1979-2019, 0.5 ) (Chen et al., 2008). In addition, we analyze daily precipitation output from 25 Global Climate Models (GCMs) participating in the Coupled Model Intercomparison Project Phase 6 (CMIP6) (Eyring et al., 2016) (Table 1). For each model, data is extracted from the historical (1976-2005) and SSP585 (2071-2100) scenarios (O'Neill et al., 2016). Analyses are performed for each model at its native resolution, and results are regridded to a common $1^{\circ}$ $\times 1^{\circ}$ grid. In SSP585, an anomalous radiative forcing of $8.5 \mathrm{~W} / \mathrm{m}^{2}$ is achieved by 2100 .

For each dataset, monthly 99th all-day (i.e., including days both with and without precipitation) percentiles of daily precipitation at each grid point are used to define extreme precipitation events, and events within each season (winter: DJF; spring: MAM; summer: JJA; and fall: SON) are analyzed together. For information, we show on Figure S1 the average seasonal 99th daily precipitation percentiles. For the SSP585 CMIP6 runs, we define extreme events both using the SSP585 percentiles ("scenario-dependent threshold") and also the historical percentiles ("historical threshold"). The former choice allows us to detect changes in the temporal dependence of "fixed-probability" extreme events, regardless of changes in extreme precipitation magnitude, while the second focuses on trends in the frequency and temporal dependence of "fixed-magnitude" extreme events. The presence of temporal trends in extreme daily precipitation percentiles in the future CMIP6 simulations was not found to impact our results. We tested this assumption by using 10-year moving windows to define extremes for CMIP6 models and it made no significant difference (Figures S2 and S3), likely because at the 30 -year timescale inter-annual variability in extreme precipitation magnitude dominates over climate-change induced trends. Therefore, in the following, fixed percentiles were used for the 2071-2100 period in the scenario-dependent threshold analysis.

As mentioned in the introduction, taking a seasonal approach allows to remove much of the influence of the seasonality in the magnitude and occurrence of extreme precipitation. Here, we choose to define "locally-extreme" events in the daily precipitation time series by using monthly precipitation percentiles. This yields a rather constant rate of occurrence across the year, and allows to statistically assess clustering and its significance more easily. By defining extreme events using a grid-point dependent threshold, we also remove the influence of spatial variability in extreme precipitation percentiles. 
With these definitions, we obtain binary daily time series of extreme event occurrence and non-occurrence. Because daily precipitation at extreme quantiles can exhibit short-term temporal dependence, typically due to the persistence of the associated weather systems, we implement a declustering procedure to remove this dependence so as to focus exclusively on clustering at longer (weekly and above) timescales. Following Barton et al. (2016), a standard runs declustering (Coles, 2001) is applied to the binary series, which consists in regrouping extreme events separated by less than $r$ days as a single event, which is (arbitrarily) chosen to occur on the day of maximum precipitation. A run length $r$ of 2 days is typical for the extratropics (see Barton et al. (2016) and references therein). For the tropics, the analysis of the duration of convective events also suggests a timescale of 1-2 days (Roca et al., 2020). Therefore a run length $r$ of 2 days was used in this analysis. For robustness, we also checked our results with run lengths of 3 and 4 days, and the main conclusions remained unchanged (Figure S4).

To quantify clustering in the occurrence of precipitation extremes, we rely on Ripley's K function (Ripley, 1981). Ripley's K function is a tool that is typically used to analyze clustering behaviors at varying spatial scales in spatial point process data, but it can also be used for point processes in one dimension along the time axis. Denoting our binary time series as $\left(Y_{t}\right)_{t=1 . . N}$, Ripley's K function is defined for a time lag $n$ as:

$K(n)=\lambda^{-1}\left(\mathbb{E}\left[\sum_{k=-n}^{n} Y_{t+k} \mid Y_{t}=1\right]-1\right)$

where $\lambda$ is the average density of events in the time series. For simplicity, we drop the $\lambda^{-1}$ factor since it does not affect the results. Thus, $K(n)$ is equal to the average number of events within $n$ time steps (in our case, days) of a randomly chosen event, not counting that event. $K$ can be estimated with a simple empirical estimator $\hat{K}$ as in Barton et al. (2016).

The significance of the temporal clustering of extreme events is assessed, at each grid point and in each dataset at its native resolution, by comparing the sample $\hat{K}$ values to the set of $K$ values obtained from a Monte-Carlo sampling of 5000 simulated homogeneous Poisson processes with the same average event density $\lambda$ as the sample series (hence why dropping $\lambda$ in Eq. (1) does not matter). Homogeneous Poisson processes, in which events occur independently from each other, exhibit complete temporal randomness, and have been used before to test for the significance of clustering (Mailier et al., 2006; Vitolo et al., 2009; Villarini et al., 2011; Barton et al., 2016). For a given $n$, we define an empirical $p$-value for the sample series' Ripley's $\mathrm{K}$ as one minus its percentile rank in the corresponding Monte-Carlo sample. A series for which $\hat{K}(n)$ is larger than all values in the MonteCarlo sample will thus have a $p$-value of zero. The sample series is then said to exhibit a significant clustering pattern if its $p$-value is lower than $p^{*}$, with

$p^{*}=\max _{i}\left(p_{(i)} \mid p_{(i)} \leq \frac{i}{N} \alpha\right)$

where $p_{(i)}$ are the sorted p-values from all $N$ available grid points and $\alpha=0.05$ is the chosen control significance level. This procedure controls the false discovery rate when analyzing the results of multiple hypothesis tests (Wilks, 2016). In other words, clustering significance is detected when the sample series' $\hat{K}(n)$ is larger than the bottom $100\left(1-p^{*}\right) \%$ values from the corresponding Monte-Carlo sample (Fig. 1).

By testing for different values of $n$, clustering can thus be quantified at any timescale, but for simplicity we summarize the results across four timescales: $5-15,15-25,25-35$ and 35-45 days. If clustering is significant for the majority of $n$ values within each of these intervals, then we consider clustering to be significant for the whole interval. Note that since Ripley's K value for step $n$ is an estimate of the average number of extreme events within $n$ days of any randomly chosen extreme event, in practice the "clustering size" associated with step $n$ is

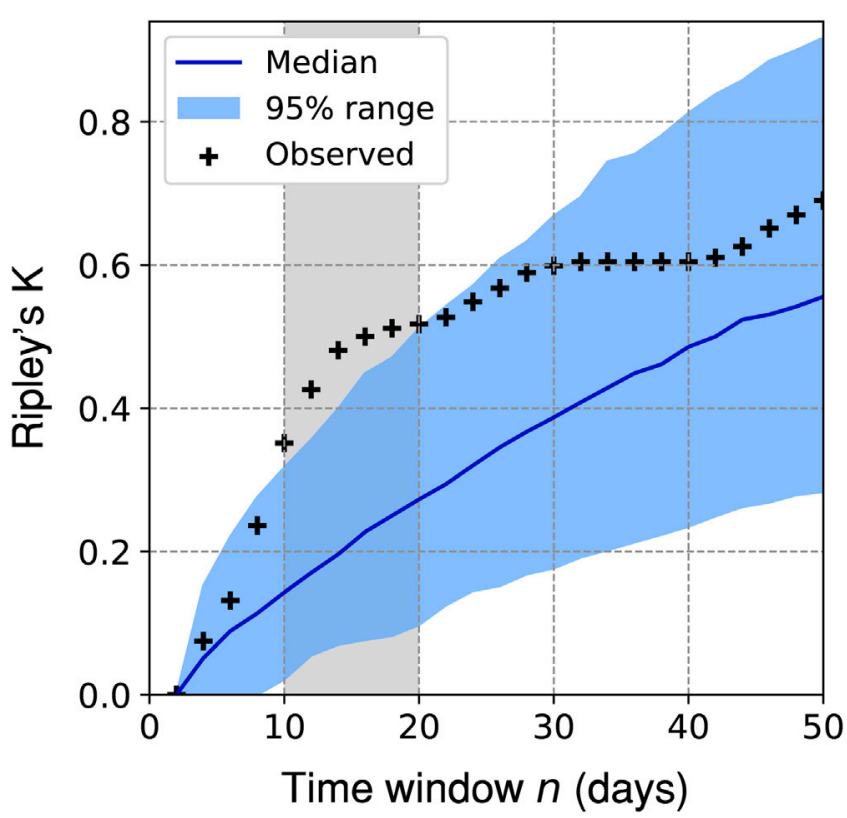

Fig. 1. Assessment of clustering significance with Ripley's K: example of Ripley's K values obtained from an observed time series (black crosses), and the corresponding Monte-Carlo sample median (blue line) and $95 \%$ range (blue shading). In this case, the observed series exhibits significant clustering over the 10-20 day timescale.

equal to $2 n+1$. Note also that significance is determined by comparing against a sample of homogeneous Poisson series with the same event probability, and not the same number of events, which makes our assessment of significance rather conservative. In CMIP6 simulations, the significance of clustering is assessed for each model and scenario separately as well as, in the SSP585 runs, for each extreme event definition (using historical or scenario-dependent daily precipitation thresholds).

\section{Results}

\subsection{ERA5}

Wide areas with large $K$ values, significantly different from those expected from a random Poisson process, can be found year-round in the ERA5 data. Specifically, all four seasons exhibit a general pattern of high $\mathrm{K}$ values and significant clustering over tropical oceans $\left(20^{\circ} \mathrm{S}-\right.$ $20^{\circ} \mathrm{N}$ ), particularly along the equator in the Central and Eastern Pacific (Figs. 2 and 3). By contrast, Ripley's $\mathrm{K}$ values are much lower in the extratropics, and patterns of significance exhibit less spatial coherence. A few regions with higher $\mathrm{K}$ values stand out outside the tropics, however. In the Northern Hemisphere, the Eastern North Atlantic generally exhibits significant clustering in DJF, particularly between $30-40^{\circ} \mathrm{N}$, extending into Morocco and the Iberian Peninsula (Fig. 3-a), and to a lesser extent in MAM, when significance extends over a band stretching from the Caribbean to the British Isles (Fig. 3-b). Northeastern Russia also experiences significant clustering during SON, as does Alaska, to a lesser extent, in DJF and SON. Clustering is significant over the central North Pacific $\left(20-40^{\circ} \mathrm{N}\right)$ in DJF and MAM, with the region of significance extending over Western North America in winter. Closer to the tropics, some clustering significance can be seen in Southwest Asia and the Middle East across much of the year. In the Southern Hemisphere, Australia stands out, chiefly during SON, along with a region of the subtropical South Pacific around $30^{\circ} \mathrm{S} / 110^{\circ} \mathrm{W}$ in SON and DJF. In the tropics, the dominant signal is concentrated over the equatorial Pacific east of the dateline, with a zonal extent of $15-20^{\circ}$ during DJF and MAM, but only about $10^{\circ}$ in JJA and SON. In addition, 
the Horn of Africa, as well as the neighboring ocean, also exhibit significant clustering, particularly during SON and DJF, as does the Maritime Continent in JJA and SON and Northeastern Brazil in DJF and MAM.

These results are generally robust across timescales, as can be seen from Figs. 4 and 5, with important differences however between the tropics and extratropics. Over the tropical oceans, clustering significance is not very dependent on the timescale. By contrast, outside the tropics and over tropical land, significance tends to weaken as the time window increases. Over Alaska and the Eastern Atlantic, for instance, clustering significance is largely concentrated at timescales of 25 days and less. While most regions exhibit more clustering significance at shorter timescales, the opposite is generally not true: there is hardly any area of the world where clustering becomes more significant at longer time windows.

\subsection{Comparison of datasets}

We now turn to the other satellite- and gauge-based precipitation datasets. Overall, significance patterns tend to be quite consistent across the datasets, and the spatial coherence of areas exhibiting clustering significance is strengthened compared to the ERA5-only analysis (Fig. 6). This is particularly true for the tropics, where there is strong agreement on the significance of the clustering over the equatorial Pacific, the Western Indian Ocean, Northeastern Brazil or the Maritime Continent, but also outside the tropics over Australia (particularly in SON), the Southeastern Indian Ocean (in DJF) and Southwest Asia. Similarly, the datasets all point towards significant clustering over the Eastern Atlantic during DJF and to a lesser extent during MAM. The robustness of the results at high latitudes $\left(>50^{\circ}\right)$ is more difficult to assess since fewer datasets are available there (ERA5 over land and ocean and CPC over land only, whose accuracy is limited by the scarceness of stations at such latitudes), but at least there seems to be agreement on significant clustering over Alaska and Northeastern Russia. In addition, the comparison of the various datasets highlights a few regions that did not particularly stand out in ERA5 alone, but where other datasets point to significance in the clustering of precipitation extremes: the Western US and Mexico during DJF and MAM, the Western Sahel in DJF, Northern Chile in SON, the subtropical North Pacific east of Hawaii (especially in JJA) and Africa's Great Lakes region during JJA.

To highlight differences between the datasets, we show in Fig. 7 zonal-mean clustering significance for ocean and land separately (results from CMIP6 models are discussed in the next section). Over the oceans, within the $40^{\circ} \mathrm{S}-40^{\circ} \mathrm{N}$ band, TRMM and CMORPH are in relatively good agreement, while ERA5 generally exhibits a similar significance profile but of larger magnitude. This can also be seen in Figs. 3 and 6, which highlight that datasets other than ERA5 tend to show less clustering significance over the tropical oceans. GPCP is clearly the outlier: it indicates much more clustering, and over a wider latitude range, than the other datasets, particularly north of the equator in JJA and SON (Fig. 7-c,d). This might be related to the tendency of GPCP to underestimate extreme precipitation magnitudes, and thus to exhibit daily time series with light tails (Bador et al., 2020). In high latitudes of both hemispheres, particularly during their respective cold seasons, CMORPH diverges from ERA5 by showing anomalously high levels of significance, possibly due to this product's limited performance in capturing cold-season precipitation and snowfall (Xie et al., 2017).

By contrast, disagreement between the datasets is stronger over land, notably during the DJF and JJA seasons. TRMM, ERA5 and GPCP agree on the more frequent occurrence of clustering significance in the tropical band $\left(20^{\circ} \mathrm{S}-20^{\circ} \mathrm{N}\right)$ during MAM and SON (Northeastern Brazil, Northern Australia and the Maritime Continent) and around $30^{\circ} \mathrm{N}$ in SON (Southwest Asia). At low to mid-latitudes, significance tends to be weaker in GPCP and CMORPH, possibly due to them being short records for which significance is harder to assess. As over oceans, clustering significance in CMORPH often tends to increase rapidly beyond $40^{\circ} \mathrm{N} / \mathrm{S}$.

\subsection{CMIP6 and future changes}

Finally, we turn to the analysis of CMIP6 model output for the historical (1976-2005) and future (2071-2100) periods. Fig. 8 shows the multi-model mean clustering significance of daily precipitation extremes for each season. Most of the main patterns identified in ERA5 and the observation-based datasets can also be found in the CMIP6 models: widespread significance of clustering over oceans around the equator, particularly in the Pacific, and clustering limited to a handful of hotspots in the extratropics. In particular, many of the regions discussed in Sections 3.1 and 3.2 are also captured by CMIP6 models. The latter indicate significant clustering over the eastern North Atlantic in DJF and MAM, with a poleward shift and westward extension of the region of significance during MAM, as in Fig. 6. CMIP6 models also tend to exhibit significant clustering over Alaska and Northeastern Russia (mainly in DJF), Australia and the Maritime Continent (JJA, SON), Eastern Africa, Southwest Asia and the Middle East. Over the subtropical North Pacific, the GCMs also show clustering, but more structured spatially during DJF and MAM, with clustering concentrated along a band extending from Hawaii to California, which does not stand out in ERA5 and observation-based datasets (Fig. 6-a,b). Similarly, the significance of the clustering over Southwest Asia appears overestimated by CMIP6 models during DJF and MAM. CMIP6 models also agree quite strongly on the presence of significant clustering over the equatorial Atlantic during JJA and SON, by contrast with the other datasets. As to zonal-mean values, they are overall consistent with other datasets which are for the most part contained within the range of CMIP6 values (Fig. 7). The notable exceptions are GPCP over ocean grid-points, and CMORPH polewards of $40^{\circ} \mathrm{N} / \mathrm{S}$. The CMIP6 multi-model mean follows TRMM somewhat closely. Interestingly, the inter-model spread is larger over land, especially in JJA and SON.

Future changes in Ripley's K values and associated clustering significance for precipitation extremes defined with a scenario-dependent threshold are shown on Figs. 9 and 10, respectively. The largest changes in areas that exhibit significant clustering are found over the tropical oceans, unsurprisingly since they exhibit the largest Ripley's $\mathrm{K}$ values and most significance in the historical climate. One finds, however, a strong seasonality in projected tropical changes. Shoulder seasons (MAM and SON) are characterized by decreases in Ripley's K values and lower significance along the equator, particularly on the side of the summer hemisphere, and the opposite over the subtropics of the winter hemisphere (Fig. 10-b,d). In DJF, the changes show no clear pattern, while in JJA, large changes are concentrated along the equator (increasing significance over the Eastern Pacific and Indian Oceans, but decreasing significance over the Atlantic and Western Pacific). Over land, changes in clustering significance are also projected over a few regions. Clustering over Alaska and southwestern Europe increases slightly during MAM in the SSP585 scenario, as well as over Australia during JJA and SON and southeastern Brazil during SON. In Southwest Asia, where clustering is particularly significant in the historical climate, projections indicate a weak increase of clustering in JJA and SON over the Arabian Peninsula, but a slight decrease over Iran and Pakistan.

For the historical threshold analysis, projected changes in Ripley's $\mathrm{K}$ values exhibit the same pattern as future changes in extreme precipitation magnitude (e.g., Pfahl et al., 2017): substantial declines over the subtropical descent regions and large increases along the equator and at mid-to-high latitudes (Fig. 11). In terms of clustering significance, the picture is quite different (Fig. 12). We remind the reader that while the frequency of extreme events is not equal to $1 \%$ in the historical threshold analysis (since historical 99th daily precipitation percentiles are used for the future SSP585 series), one can still assess the significance of extreme event clustering by comparing to simulated series with the same event frequency. Clustering significance is enhanced over much of the world, particularly along the equator, over the subtropics and in the high northern latitudes. It increases notably on the eastern margins 
a

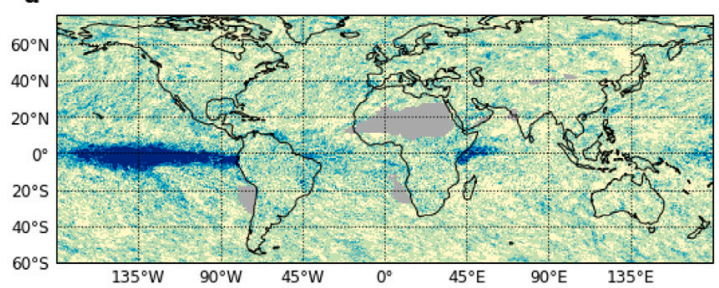

c

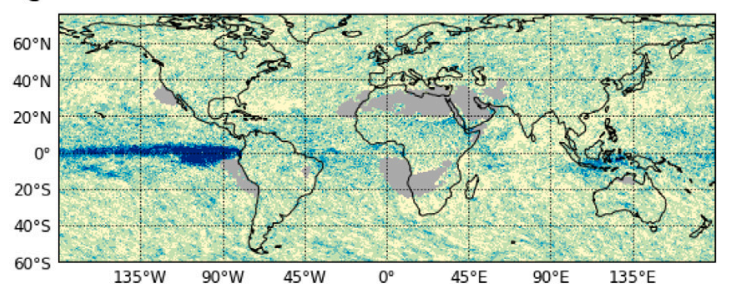

b

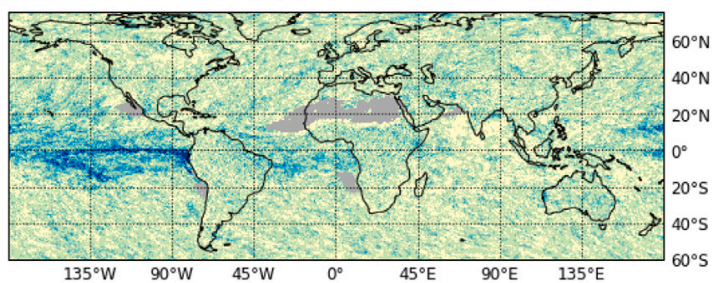

d
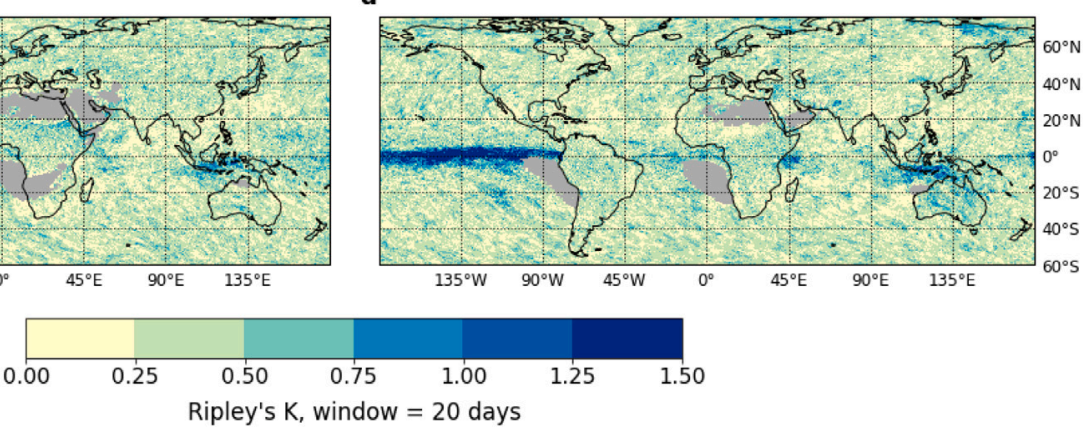

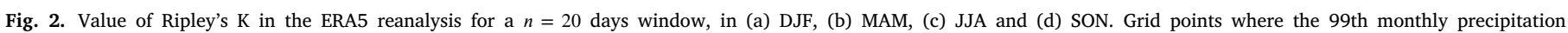
percentile is lower than $1 \mathrm{~mm}$ are shown in gray. (For interpretation of the references to color in this figure legend, the reader is referred to the web version of this article.)

a

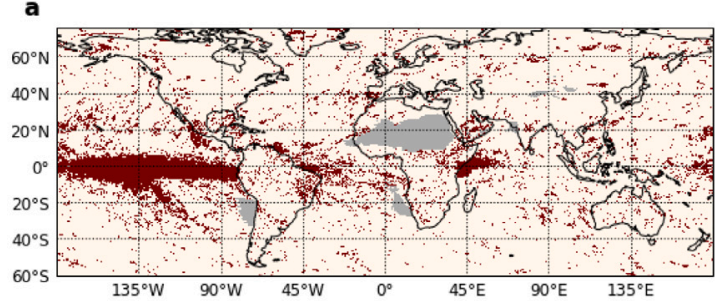

C
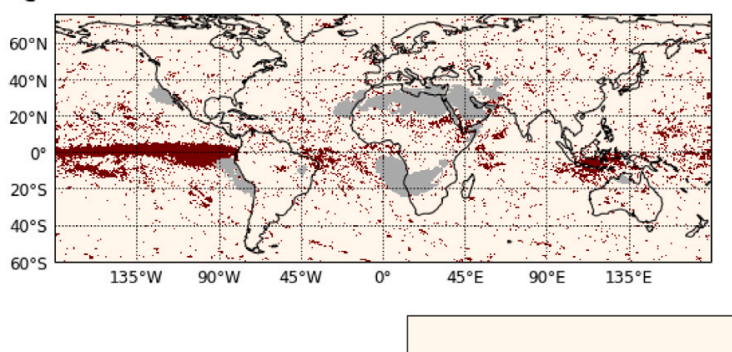

Not significant b

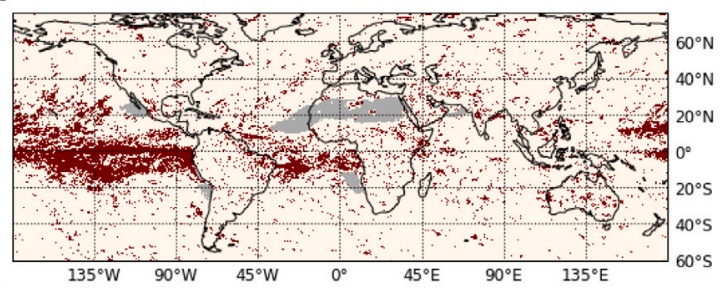

d

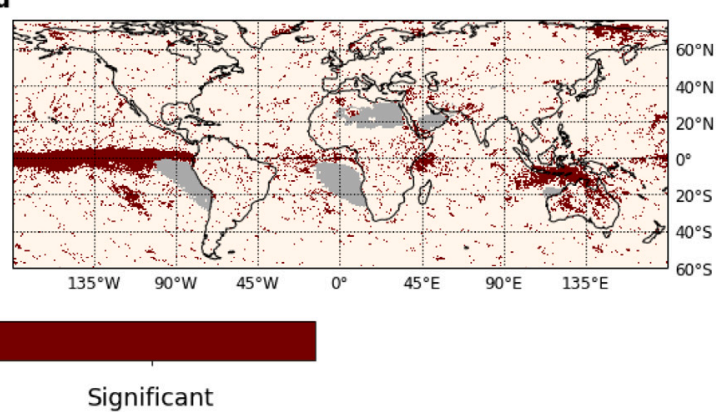

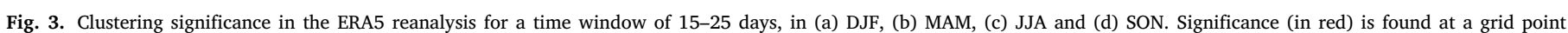

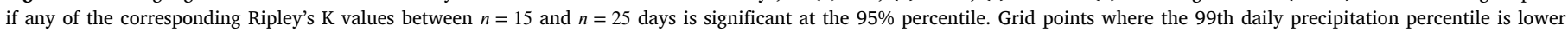
than $1 \mathrm{~mm}$ are shown in gray. (For interpretation of the references to color in this figure legend, the reader is referred to the web version of this article.)

of the subtropical North Atlantic and Pacific Oceans in DJF and MAM, with potential implications in terms of climate risk. Southwest Asia also stands out due to a substantial year-round increase in clustering, as do Alaska in DJF and MAM, and Australia in all seasons except DJF.

\section{Discussion}

\subsection{Physical drivers of clustering}

The application of Ripley's K function as a tool to assess the temporal dependence in the occurrence of extreme precipitation makes it possible to identify a number of regions around the world where that dependence is strong. In addition, compared to most previous studies, we define extreme events based on monthly daily precipitation percentile, which removes the seasonal signal in extreme precipitation magnitude. This approach therefore highlights clustering driven by inter-annual variability or sub-seasonal dynamics. The analysis of significance timescales can suggest mechanisms responsible for the clustering. In the tropics, clustering significance is independent of timescale (Figs. 4, 5), from a few days to several months. In other words, for a given season, many extreme precipitation events will occur within the same year. Long clustering timescales in the tropics suggest an important role of sea-surface temperature (SST) anomalies, which typically persist for months, and therefore SST-driven interannual variability in extreme precipitation occurrence may be the dominant cause of the clustering. The likelihood of extreme precipitation in the tropical band is known to be influenced by large-scale modes of SST variability, most notably the El Niño Southern Oscillation (ENSO) (Curtis et al., 2007). ENSO's influence on extreme precipitation is felt over land (Kenyon and Hegerl, 2010), but primarily over oceans through its impact on the position of the Inter-Tropical Convergence Zone (ITCZ) (Adam et al., 2016). ENSO's influence also extends on 
a
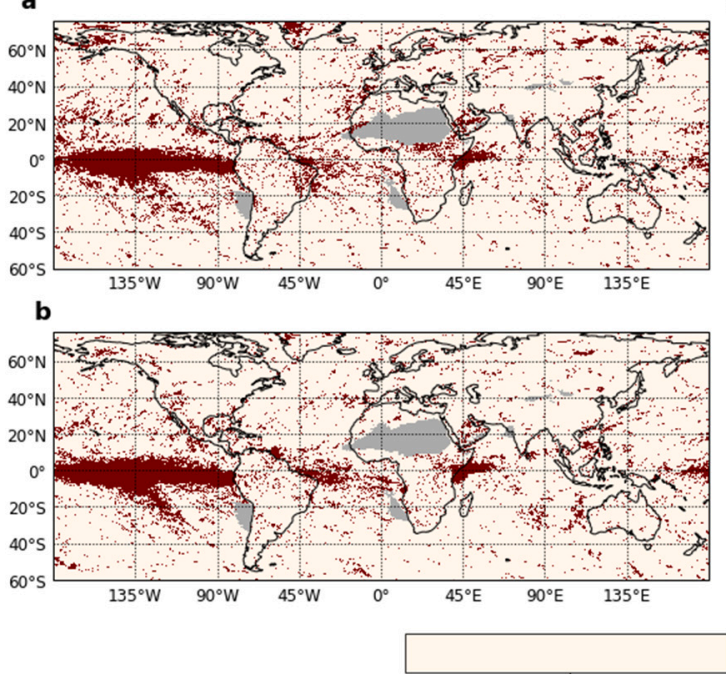

Not significant
C
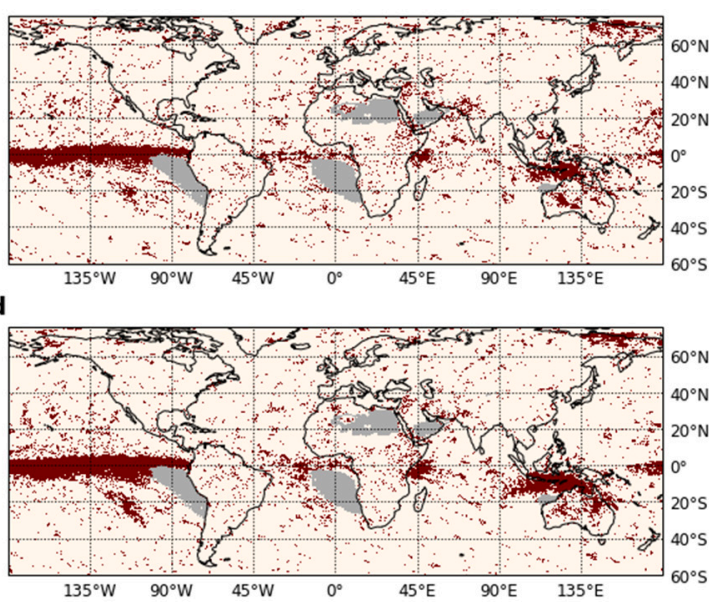

Significant

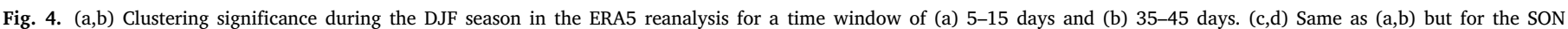

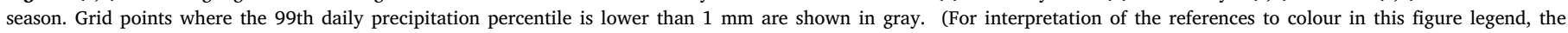
reader is referred to the web version of this article.)
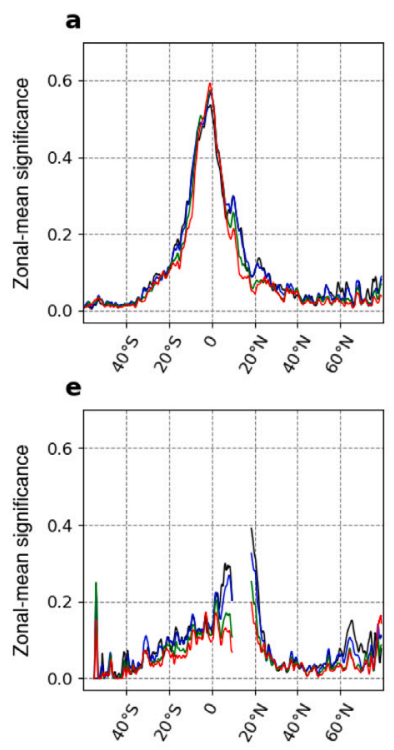
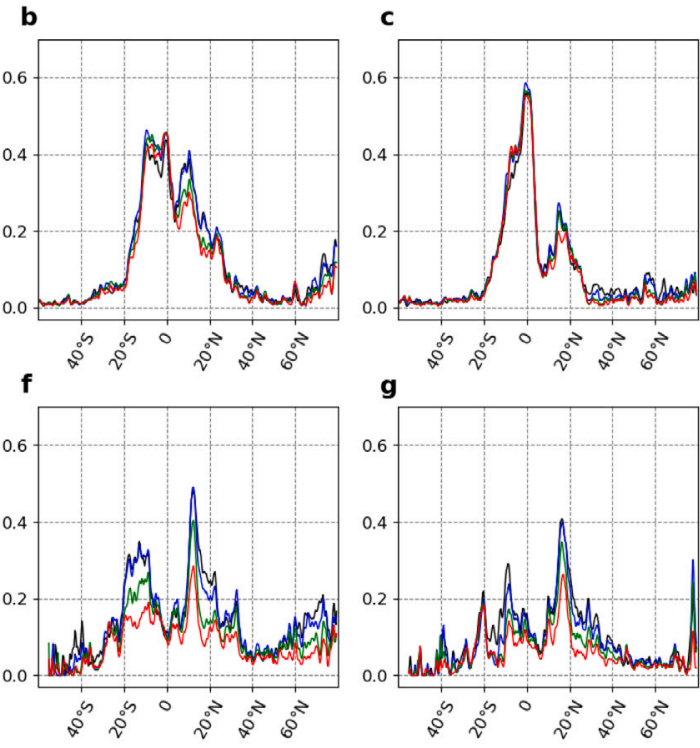

\section{$\mathbf{g}$}
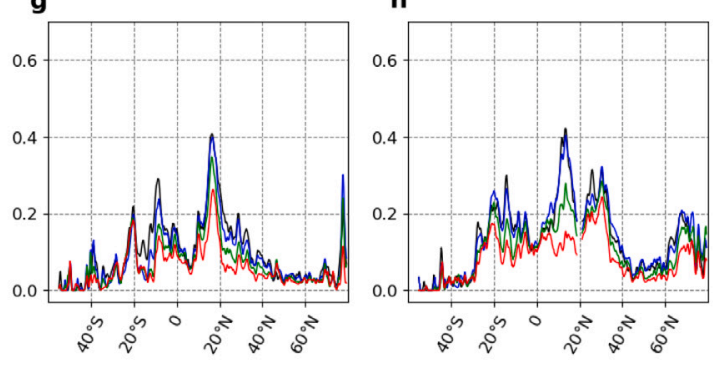

5-15 days
$-15-25$ days

$25-35$ days
$-\quad 35-45$ days

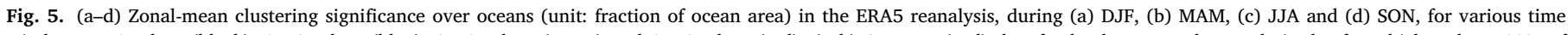

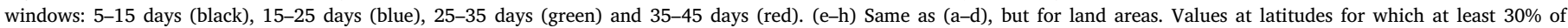
the data points have a 99th monthly precipitation percentile lower than $1 \mathrm{~mm}$ are not shown.

the position of the Atlantic ITCZ (Münnich and Neelin, 2005) which may explain why this region also exhibits some sub-seasonal clustering. The conclusion is likely similar over the Maritime Continent, another region exhibiting large levels of clustering significance, where ENSO and the Indian Ocean Dipole are known to influence ITCZ position at inter-annual timescales (Freitas et al., 2017). In this region, the Madden-Julian Oscillation may also play a role (Ratan and Venugopal, 2013). The IOD also drives inter-annual variability in extreme precipitation over the western Indian Ocean coastline (Marchant et al., 2007) and may explain the significant clustering regions of Eastern Africa and Southwest Asia.
By contrast, in the extratropics, clustering significance is mostly found at shorter timescales of one to four weeks. Unlike in the tropics, extratropical extreme precipitation tends to be linked to synoptic weather systems and atmospheric rivers (e.g., Pfahl and Wernli, 2012; Catto and Pfahl, 2013; Pfahl et al., 2014), which may exhibit clustering forced by sub-seasonal persistence in large-scale climate modes such as the Arctic Oscillation (Kenyon and Hegerl, 2010; Yang and Villarini, 2019). It remains to explain however why clustering is concentrated over certain regions like the subtropical Eastern Atlantic. Interestingly, extratropical land regions where extreme precipitation occurrence is known to be impacted by ENSO, like North America or Southeastern Asia (Kenyon and Hegerl, 2010) do not exhibit significant clustering. 
a

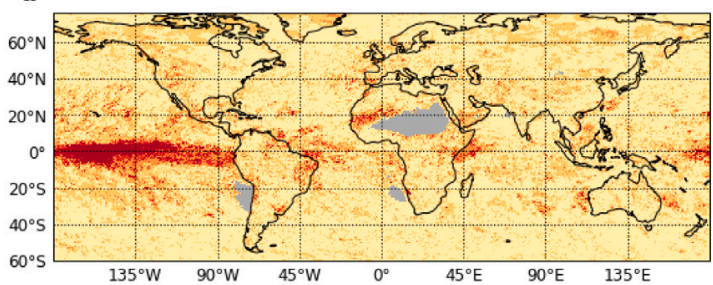

c

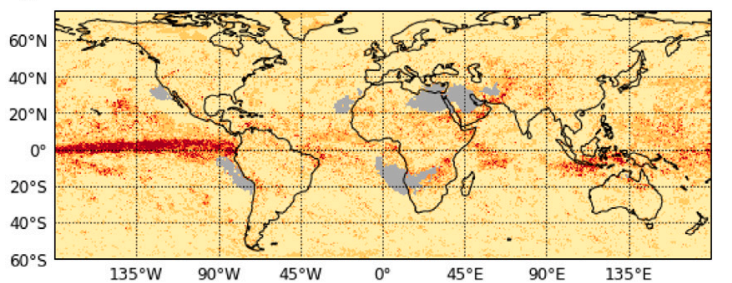

b

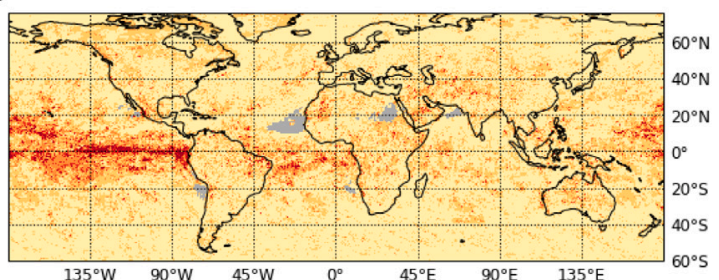

d

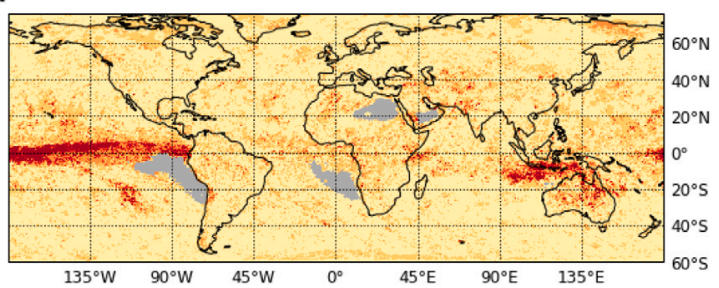

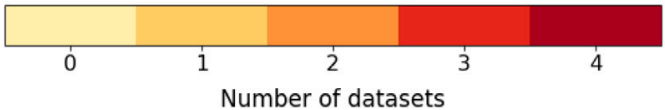

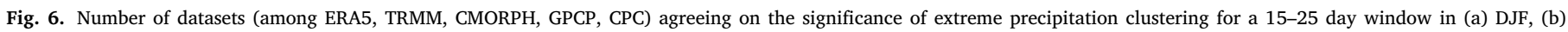

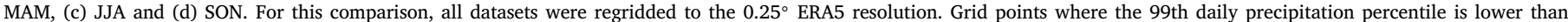
$1 \mathrm{~mm}$ in at least two datasets are shown in gray. (For interpretation of the references to color in this figure legend, the reader is referred to the web version of this article.)
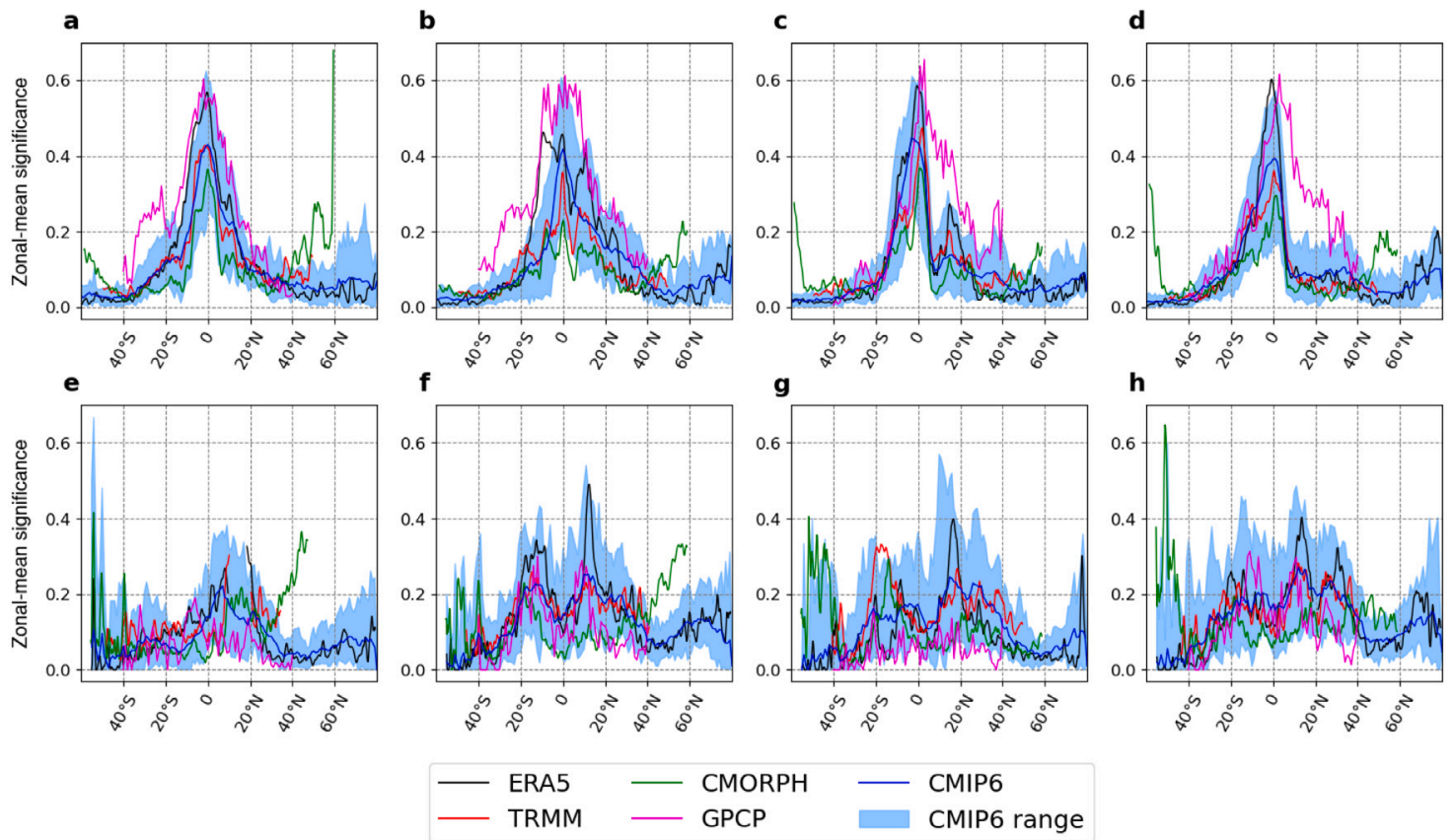

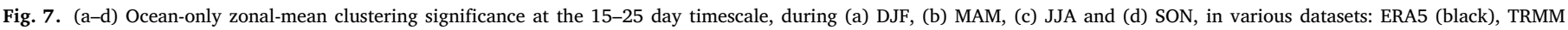

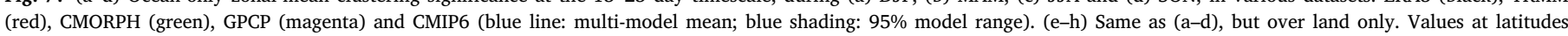
for which at least $30 \%$ of the data is missing (99th daily precipitation percentile lower than $1 \mathrm{~mm}$ ) are not shown.

Our approach here has been purely statistical, and our discussion of physical drivers is speculative. Future work should aim at identifying physical explanations for the sub-seasonal temporal clustering highlighted in our results; in particular, potential links between persistence in atmospheric dynamics and temporal clustering of precipitation extremes.

\subsection{Link to surface impacts}

Our description of sub-seasonal clustering of extreme precipitation relies on monthly timescales to define precipitation extremes and on spatially-dependent extreme precipitation thresholds. This approach highlights temporal dependence in the occurrence of precipitation extremes after removing seasonality in extreme precipitation magnitude, and it does not focus on risks linked to sub-seasonal clustering of these extremes. Indeed, precipitation accumulations associated with clusters of extremes vary significantly depending on the region and time of year, as do their potential surface impacts. Clustering may thus be significant for a given place and season, but this does not mean that clusters of precipitation extremes represent a major climate risk to that area in that season. Contrarily, even where clustering is statistically non-significant, clusters, rare as they may be, may still pose major risks for instance through large precipitation accumulations. Still, a simple global analysis of the fraction of the top-10 largest 


\section{a}

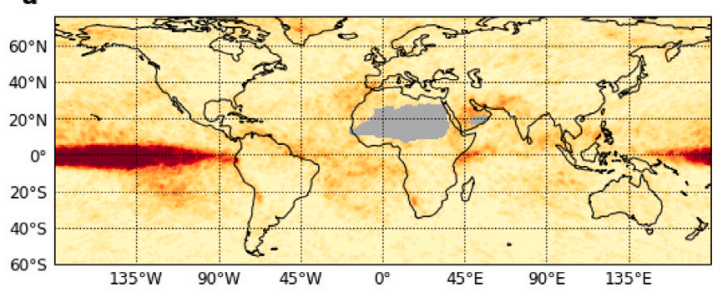

c

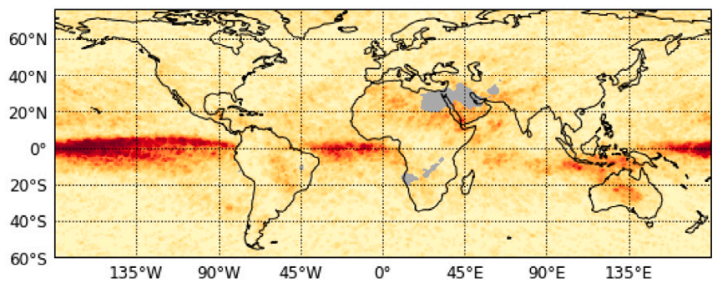

b

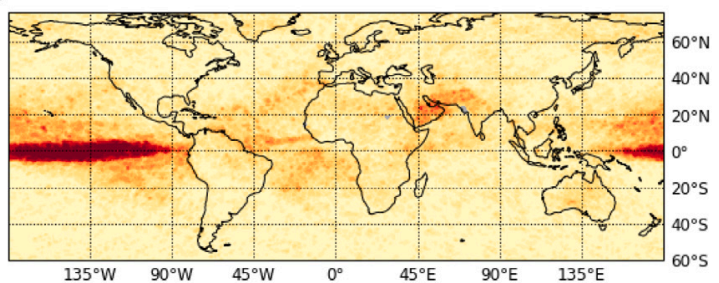

d

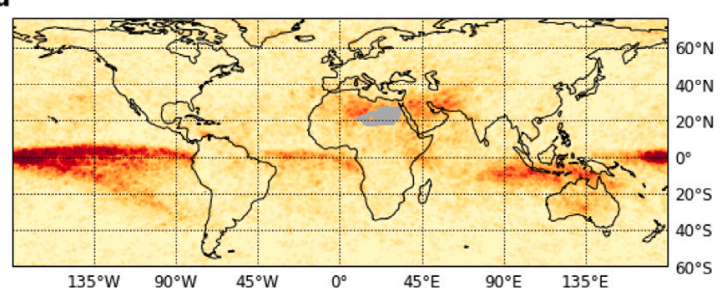

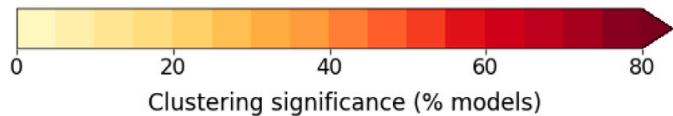

Clustering significance (\% models)

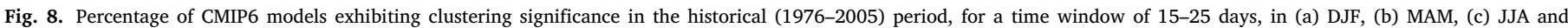

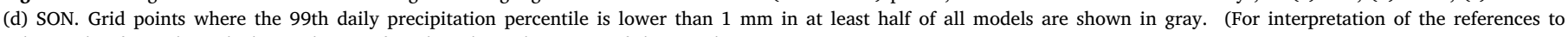
color in this figure legend, the reader is referred to the web version of this article.)

\section{a}

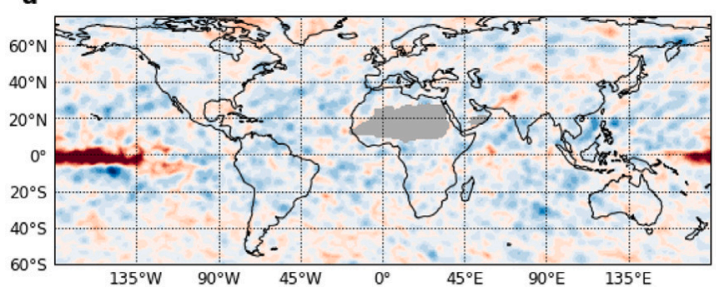

\section{c}

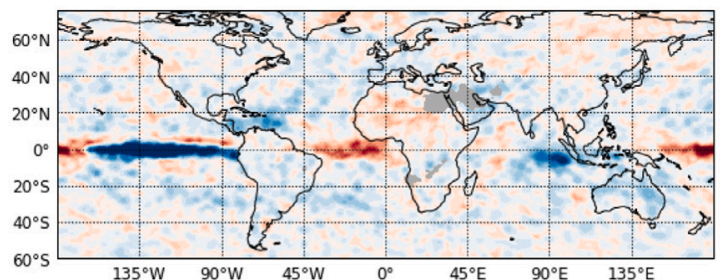

b

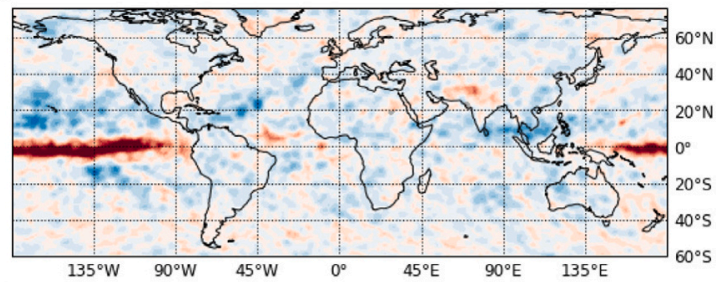

d

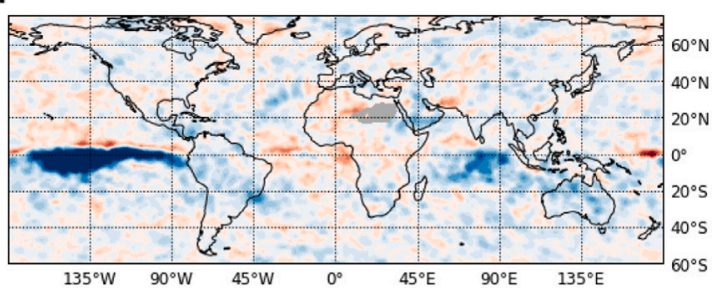

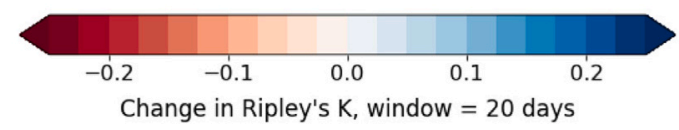

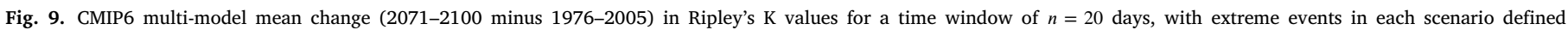

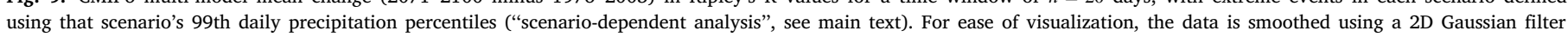

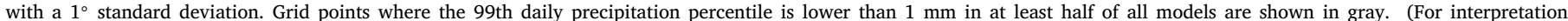
of the references to color in this figure legend, the reader is referred to the web version of this article.)

21-day precipitation accumulation episodes in ERA5 that co-occurred with at least two extreme precipitation events shows that, even when defining extreme events based on monthly percentiles, clusters tend to overlap with large sub-seasonal precipitation accumulations over many of the regions exhibiting clustering significance (Fig. 13). Some of these regions (Southwestern Europe, Eastern Siberia) were also highlighted as hotspots of cluster occurrence and contribution to large precipitation accumulation by Kopp et al. (2021). In addition, many of the clustering hotspots over land, like Southwestern Europe, Eastern Africa or Australia, are semi-arid regions where rain-driven floods are a major concern. On Fig. 13 Southwest Asia during SON seems to be an outlier, possibly due to the seasonality of extreme precipitation magnitude in that region, or to biases in ERA5 extreme precipitation magnitude (Rivoire et al., 2021). Future work could refine that analysis by identifying areas where clustering is both significant and a source of major surface impacts such as floods.

\subsection{Implications of future clustering trends}

Future changes in Ripley's $\mathrm{K}$ values and clustering significance projected by CMIP6 models under the SSP585 scenario show large contrasts between the "scenario-dependent threshold" and the "historical threshold" perspectives. Using a scenario-dependent precipitation threshold changes are largely confined to the tropics and subtropics and a few key land regions (Australia, Maritime Continent, Southwest Asia and Southeastern Brazil) show non-zero trends. There, the strengthening of the temporal dependence of extreme precipitation events has important implications in terms of climate risk: not only will the 


\section{a}

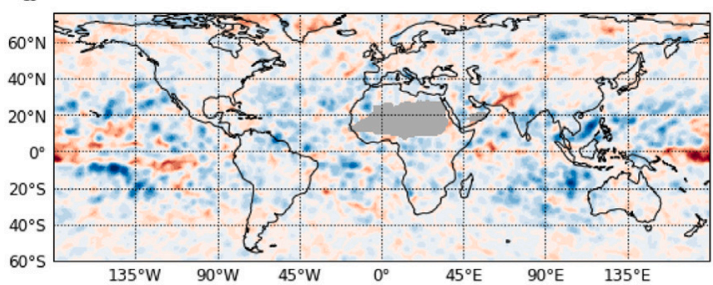

$$
\text { c }
$$

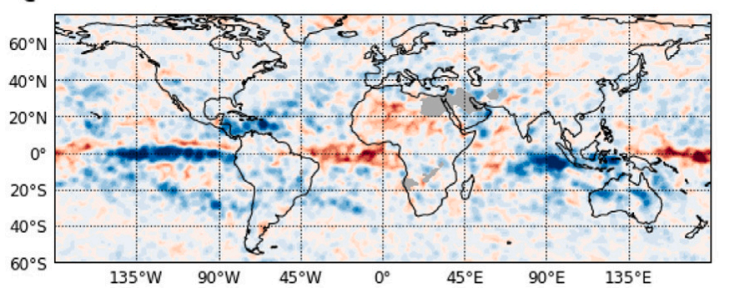

b

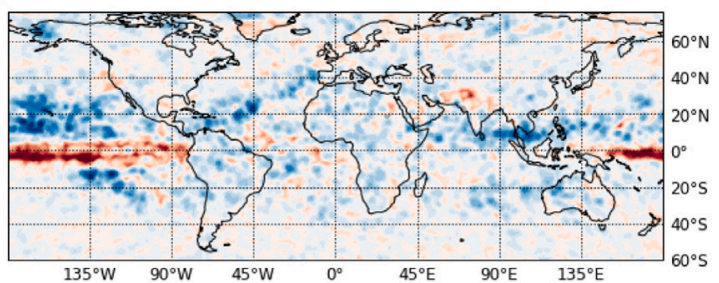

d

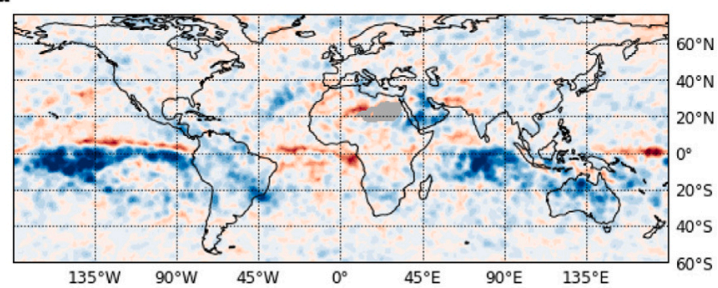

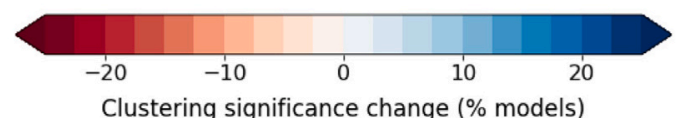

Clustering significance change (\% models)

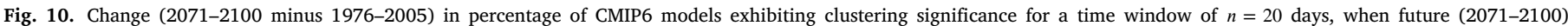

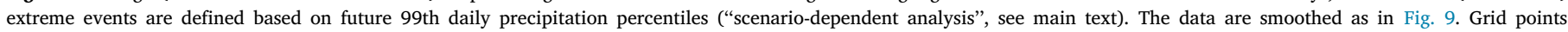

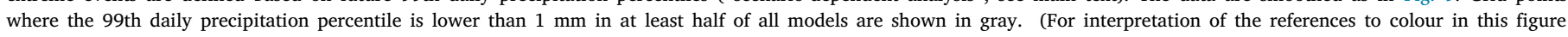
legend, the reader is referred to the web version of this article.)
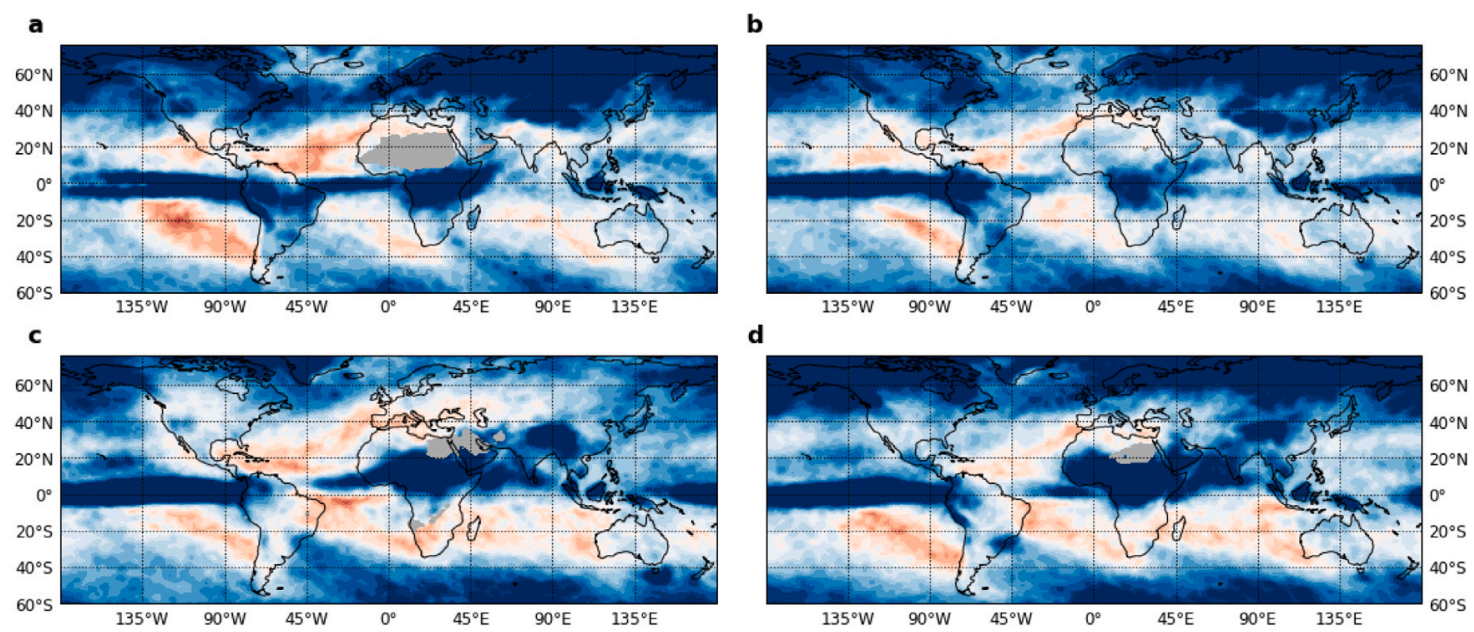

d
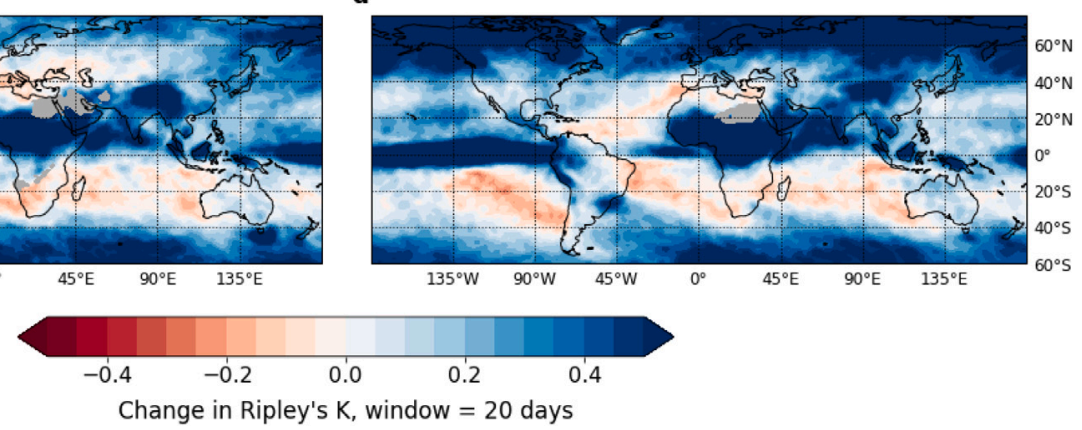

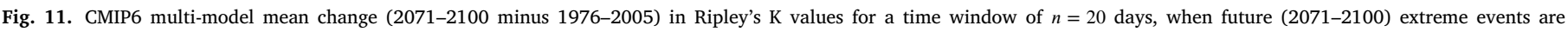

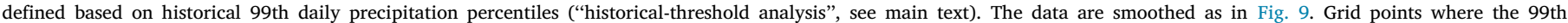

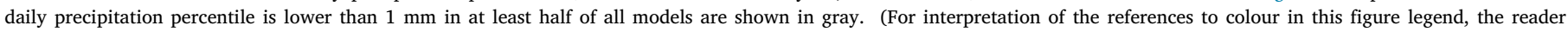
is referred to the web version of this article.)

magnitude of extreme precipitation increase (especially over Southwest Asia), but extreme events will be more clustered in time. Since interannual SST variability is likely an important driver of clustering in these regions, changes in that variability, either in its timescales or spatial patterns, may also explain the trends projected by the CMIP6 ensemble.

By contrast, as revealed by the fixed-threshold analysis, there is a clear tendency towards more significant clustering of extreme events defined by historical percentiles. In other words, GCMs robustly project increases in the persistence of historical extreme weather conditions. This increase is found over much of the world and across all seasons, though again trends are generally larger in the tropics. This increase in clustering significance may result from enhanced inter-annual variability in large-scale climate modes (ENSO, IOD, etc.), from changes in teleconnections between such modes and the likelihood of extreme precipitation occurrence, or from dynamical trends. Long-term trends in extreme precipitation magnitude seem unlikely to contribute much to this overall increase in clustering, since the patterns from Figs. 11 and 12 do not show much correspondence. Areas with large changes in extreme daily precipitation percentiles exhibit negligible changes on Fig. 12, and conversely some areas with large clustering trends are not projected to experience major changes in extreme precipitation magnitude. The translation into an assessment of future climate risk is however not straightforward. Risk in this case will depend on the duration and magnitude of clusters, but also on their frequency. Yet, for a given level of clustering, Ripley's $\mathrm{K}$ is insensitive to the average extreme event frequency in a time series. Therefore, while an increase in 


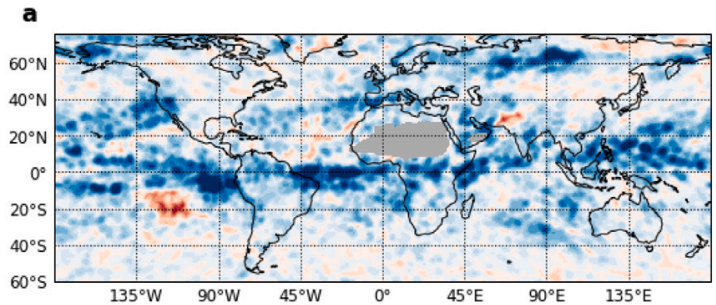

$$
\text { c }
$$

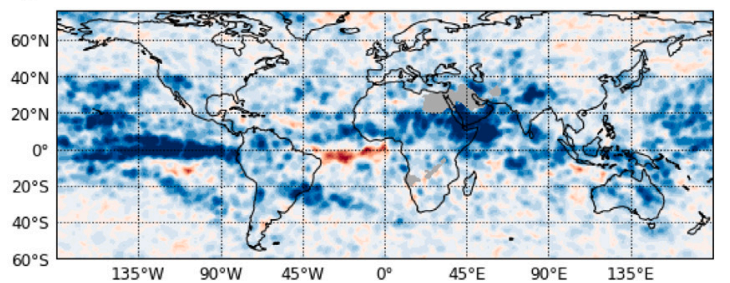

b

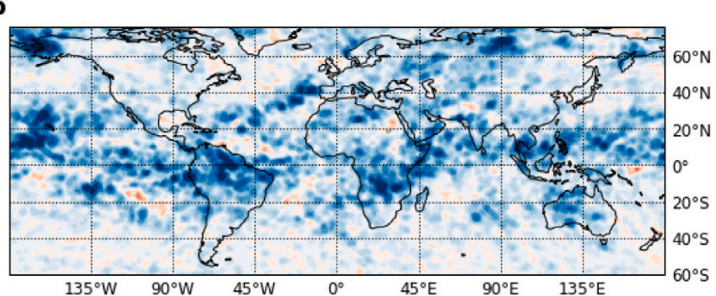

d

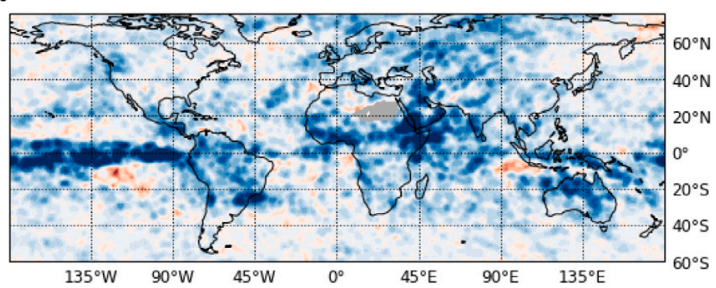

20

Clustering significance change ( $\%$ models)

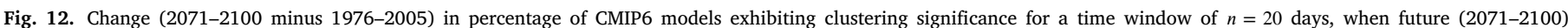

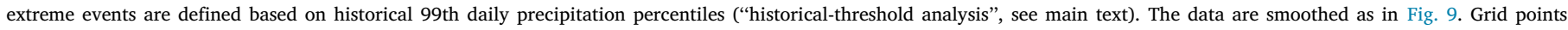

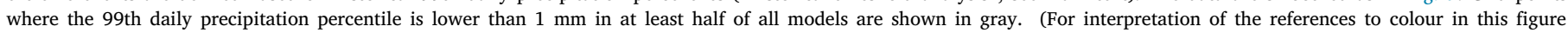
legend, the reader is referred to the web version of this article.)

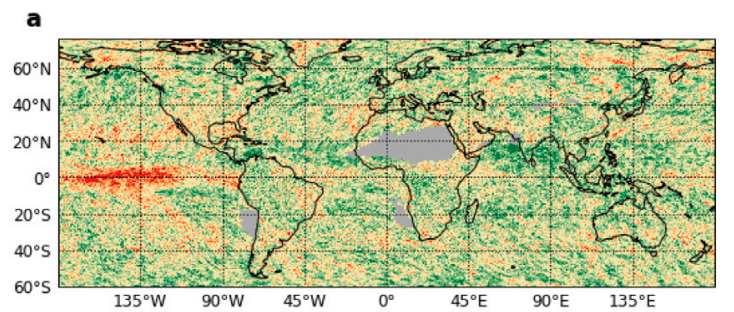

b

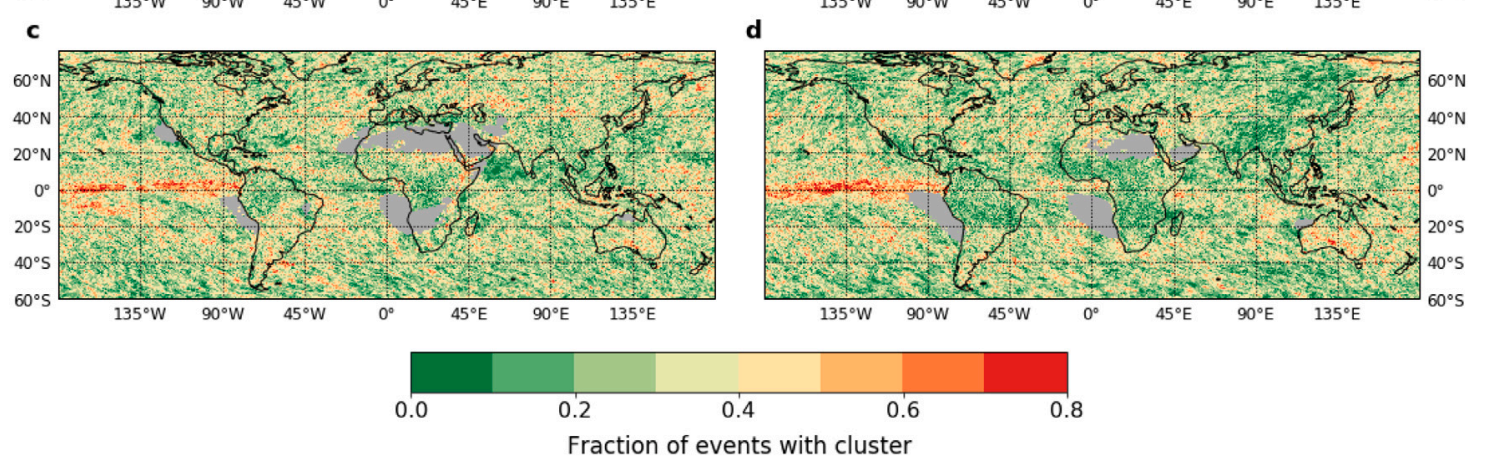

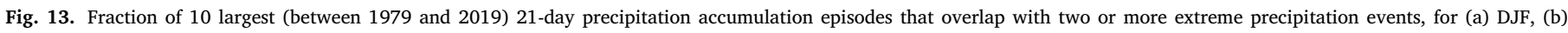
MAM, (c) JJA and (d) SON. Grid points where the 99th monthly precipitation percentile is lower than 1 mm are shown in gray. Data is from ERA5.

the persistence of current-day extremes may be projected, this analysis says nothing about future changes in their frequency.

As a final note, one should also bear in mind that the future scenario we analyzed here, SSP585, is a particularly extreme one. The analysis of projected changes in Ripley's K values and clustering significance should then not be seen as an attempt to develop future projections per se, but rather to understand at first order how the temporal dependence in extreme precipitation events may respond to large levels of greenhouse gas forcing.

\subsection{Further perspectives on persistence}

Our focus has been on sub-seasonal temporal clustering of extreme precipitation, which is one specific type of persistence in extreme

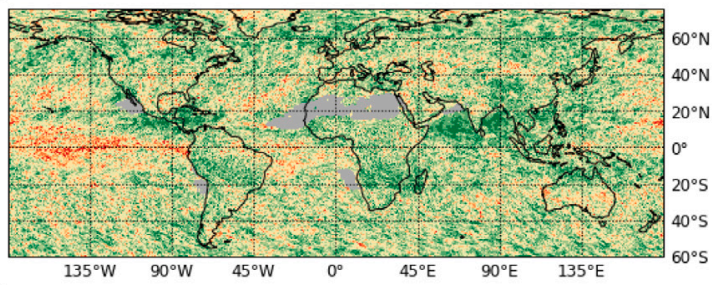

precipitation events. In particular, we did not consider persistence in the duration of individual precipitation extremes, choosing instead to consider as a single extreme event any series of extreme daily precipitation events separated by less than 2 days. Long-lasting extreme precipitation events can also result in large precipitation accumulations and are relevant from the perspective of risk assessment. Large precipitation accumulation episodes can also be driven by persistent wet, but not extremely wet, conditions. Similarly, we considered only clustering in very large precipitation extremes, and our results could be complemented by analyzing the temporal dependence of daily precipitation above smaller percentiles, or using wet-day percentiles instead of percentiles calculated from the whole distribution. 


\section{Conclusions}

This study offers a global perspective on the temporal dependence in the occurrence of daily extreme precipitation events at sub-seasonal timescales. By adopting a seasonal approach, we remove the effects of seasonality in extreme precipitation magnitude, which makes it possible to test the significance of the clustering in extreme precipitation occurrence using a simple statistical framework based on Ripley's $\mathrm{K}$ function. While at the global scale clustering dominates over the tropical oceans, several land regions exhibit significant clustering at sub-seasonal timescales of a week to a month: in DJF, Southwestern Europe, Southwestern North America, Alaska and Eastern Siberia, in SON Southwest Asia and Australia, and Eastern Africa for much of the year. Interestingly, many of these regions have semi-arid climates and may be particularly sensitive to series of heavy precipitation events occurring at short time intervals. The spatio-temporal pattern of clustering significance is robust across several datasets and generally well reproduced by the CMIP6 multi-model mean. When considering precipitation extremes with fixed probability, clustering trends in future projections under the SSP585 scenario are large in the tropics, especially over the equatorial Pacific and the Maritime Continent, and generally weak in the extratropics. Projections indicate however a strong global increase in clustering in the occurrence of present-day extremes. Our analysis opens the way for a better assessment of risk linked to clusters of extreme precipitation events, and for the understanding of their physical drivers.

\section{CRediT authorship contribution statement}

Alexandre Tuel: Designed the research, Implemented the code, Analyzed the data, Provided the figures, Wrote the manuscript. Olivia Martius: Designed and supervised the research, Wrote the manuscript.

\section{Declaration of competing interest}

The authors declare that they have no known competing financial interests or personal relationships that could have appeared to influence the work reported in this paper.

\section{Data availability}

ERA5 reanalysis data are available from 1979-2019 and can be downloaded from https://apps.ecmwf.int/datasets/. TRMM data are available from https://disc.gsfc.nasa.gov/datasets/TRMM_3B42_Daily_ 7/summary. CMORPH and GPCP data are provided by NOAA's National Centers for Environmental Information at respectively https://www.n cei.noaa.gov/data/cmorph-high-resolution-global-precipitation-estimat es/access/daily/0.25deg/and https://www.ncei.noaa.gov/data/globalprecipitation-climatology-project-gpcp-daily/access/. CPC Global Unified Precipitation data is provided by the NOAA/OAR/ESRL PSL, Boulder, Colorado, USA, from their website at https://psl.noaa.gov/. CMIP6 model output were downloaded from https://esgf-index1.ceda. ac.uk/projects/cmip6-ceda/.

\section{Acknowledgments and funding}

O.M. acknowledges support from the Swiss Science Foundation (SNSF) grant number 178751. The authors thank Yannick Barton for his help.

\section{Appendix A. Supplementary data}

Supplementary material related to this article can be found online at https://doi.org/10.1016/j.wace.2021.100348.

\section{References}

Adam, O., Bischoff, T., Schneider, T., 2016. Seasonal and interannual variations of the energy flux equator and ITCZ. Part II: Zonally varying shifts of the ITCZ. J. Clim. 29 (20), 7281-7293. http://dx.doi.org/10.1175/JCLI-D-15-0710.1, URL http://journals.ametsoc.org/doi/10.1175/JCLI-D-15-0710.1.

Bador, M., Alexander, L.V., Contractor, S., Roca, R., 2020. Diverse estimates of annual maxima daily precipitation in 22 state-of-the-art quasi-global land observation datasets. Environ. Res. Lett. 15 (3), 035005. http://dx.doi.org/10.1088/1748-9326/ ab6a22, URL https://iopscience.iop.org/article/10.1088/1748-9326/ab6a22.

Barton, Y., Giannakaki, P., von Waldow, H., Chevalier, C., Pfahl, S., Martius, O., 2016. Clustering of regional-scale extreme precipitation events in Southern Switzerland. Mon. Weather Rev. 144 (1), 347-369. http://dx.doi.org/10.1175/MWR-D-15-0205. 1, URL http://journals.ametsoc.org/doi/10.1175/MWR-D-15-0205.1.

Berghuijs, W.R., Harrigan, S., Molnar, P., Slater, L.J., Kirchner, J.W., 2019. The relative importance of different flood-generating mechanisms across Europe. Water Resour. Res. 2019WR024841, http://dx.doi.org/10.1029/2019WR024841, URL https://onlinelibrary.wiley.com/doi/abs/10.1029/2019WR024841.

Bevacqua, E., Zappa, G., Shepherd, T.G., 2020. Shorter cyclone clusters modulate changes in European wintertime precipitation extremes. Environ. Res. Lett. 15 (12), 124005. http://dx.doi.org/10.1088/1748-9326/abbde7, URL https://iopscience. iop.org/article/10.1088/1748-9326/abbde7.

Blackburn, M., Methven, J., Roberts, N., 2008. Large-scale context for the UK floods in summer 2007. Weather 63 (9), 280-288. http://dx.doi.org/10.1002/wea.322, URL http://doi.wiley.com/10.1002/wea.322.

Catto, J.L., Pfahl, S., 2013. The importance of fronts for extreme precipitation. J. Geophys. Res.: Atmos. 118 (19), 10791-10801. http://dx.doi.org/10.1002/jgrd. 50852, URL https://agupubs.onlinelibrary.wiley.com/doi/full/10.1002/jgrd.50852.

Chen, M., Shi, W., Xie, P., Silva, V.B.S., Kousky, V.E., Wayne Higgins, R., Janowiak, J.E., 2008. Assessing objective techniques for gauge-based analyses of global daily precipitation. J. Geophys. Res. 113 (D4), D04110. http://dx.doi.org/10.1029/ 2007JD009132, URL http://doi.wiley.com/10.1029/2007JD009132.

Coles, S., 2001. An Introduction To Statistical Modeling of Extreme Values. Springer Series in Statistics, Springer London, London, http://dx.doi.org/10.1007/978-14471-3675-0, URL http://link.springer.com/10.1007/978-1-4471-3675-0.

Curtis, S., Salahuddin, A., Adler, R.F., Huffman, G.J., Gu, G., Hong, Y., 2007. Precipitation extremes estimated by GPCP and TRMM: Enso relationships. J. Hydrometeorol. 8 (4), 678-689. http://dx.doi.org/10.1175/JHM601.1, URL http: //journals.ametsoc.org/doi/10.1175/JHM601.1.

Economou, T., Stephenson, D.B., Pinto, J.G., Shaffrey, L.C., Zappa, G., 2015. Serial clustering of extratropical cyclones in a multi-model ensemble of historical and future simulations. Q. J. R. Meteorol. Soc. 141 (693), 3076-3087. http://dx.doi. org/10.1002/qj.2591, URL https://onlinelibrary.wiley.com/doi/10.1002/qj.2591.

Eyring, V., Bony, S., Meehl, G.A., Senior, C.A., Stevens, B., Stouffer, R.J., Taylor, K.E., 2016. Overview of the coupled model intercomparison project phase 6 (CMIP6) experimental design and organization. Geosci. Model Dev. 9 (5), 1937-1958. http: //dx.doi.org/10.5194/gmd-9-1937-2016, URL https://gmd.copernicus.org/articles/ 9/1937/2016/.

Freitas, A.C.V., Aímola, L., Ambrizzi, T., de Oliveira, C.P., 2017. Extreme intertropical convergence zone shifts over southern maritime continent. Atmospheric Sci. Lett. 18 (1), 2-10. http://dx.doi.org/10.1002/asl.716, URL http://doi.wiley.com/10.1002/ asl.716.

Grams, C.M., Binder, H., Pfahl, S., Piaget, N., Wernli, H., 2014. Atmospheric processes triggering the central European floods in june 2013. Nat. Hazards Earth Syst. Sci. 14 (7), 1691-1702. http://dx.doi.org/10.5194/nhess-14-1691-2014, URL https: //nhess.copernicus.org/articles/14/1691/2014/.

Helbling, A., Kan, C., Vogt, S., 2006. Dauerregen, Schauer oder Schmelze-welche Ereignisse lösen in der Schweiz die Jahreshochwasser aus? Wasser Energie Luft 98, 249-254.

Hersbach, H., et al., 2020. The ERA5 global reanalysis. Q. J. R. Meteorol. Soc. 146 (730), 1999-2049. http://dx.doi.org/10.1002/qj.3803, URL https://onlinelibrary. wiley.com/doi/abs/10.1002/qj.3803.

Huffman, G.J., Adler, R.F., Morrissey, M.M., Bolvin, D.T., Curtis, S., Joyce, R., McGavock, B., Susskind, J., 2001. Global precipitation at one-degree daily resolution from multisatellite observations. J. Hydrometeorol. 2 (1), 36-50. http://dx.doi.org/10.1175/1525-7541(2001)002<0036:GPAODD>2.0.CO;2, URL http://journals.ametsoc.org/doi/abs/10.1175/1525-7541\%282001\%29002\% 3C0036\%3AGPAODD\%3E2.0.CO\%3B2.

Huffman, G.J., et al., 2007. The TRMM multisatellite precipitation analysis (TMPA): Quasi-global, multiyear, combined-sensor precipitation estimates at fine scales. J. Hydrometeorol. 8 (1), 38-55. http://dx.doi.org/10.1175/JHM560.1.

Joyce, R.J., Janowiak, J.E., Arkin, P.A., Xie, P., 2004. CMORPH: A method that produces global precipitation estimates from passive microwave and infrared data at high spatial and temporal resolution. J. Hydrometeorol. 5 (3), 487-503. http://dx.doi.org/10.1175/1525-7541(2004)005<0487:CAMTPG > 2 . 0.CO;2, URL http://journals.ametsoc.org/doi/abs/10.1175/1525-7541\%282004\% 29005\%3C0487\%3ACAMTPG\%3E2.0.CO\%3B2.

Kenyon, J., Hegerl, G.C., 2010. Influence of modes of climate variability on global precipitation extremes. J. Clim. 23 (23), 6248-6262. http://dx.doi.org/10.1175/ 2010JCLI3617.1, URL http://journals.ametsoc.org/doi/10.1175/2010JCLI3617.1. 
Kopp, J., Rivoire, P., Ali, S.M., Barton, Y., Martius, O., 2021. A novel method to identify sub-seasonal clustering episodes of extreme precipitation events and their contributions to large accumulation periods. Hydrol. Earth Syst. Sci. Discuss. http://dx.doi.org/10.5194/hess-2021-67, [Preprint]. URL https://hess.copernicus. org/preprints/hess-2021-67/.

Mailier, P.J., Stephenson, D.B., Ferro, C.A.T., Hodges, K.I., 2006. Serial clustering of extratropical cyclones. Mon. Weather Rev. 134 (8), 2224-2240. http://dx.doi.org/ 10.1175/MWR3160.1, URL http://journals.ametsoc.org/doi/10.1175/MWR3160.1.

Marchant, R., Mumbi, C., Behera, S., Yamagata, T., 2007. The Indian ocean dipole: the unsung driver of climatic variability in East Africa. Afr. J. Ecol. 45 (1), 4-16. http://dx.doi.org/10.1111/j.1365-2028.2006.00707.x, URL http://doi.wiley. com/10.1111/j.1365-2028.2006.00707.x.

Martius, O., et al., 2013. The role of upper-level dynamics and surface processes for the Pakistan flood of July 2010. Q. J. R. Meteorol. Soc. 139 (676), 1780-1797. http://dx.doi.org/10.1002/qj.2082, URL http://doi.wiley.com/10.1002/qj.2082.

Merz, B., Nguyen, V.D., Vorogushyn, S., 2016. Temporal clustering of floods in Germany: Do flood-rich and flood-poor periods exist? J. Hydrol. 541, 824-838. http://dx.doi.org/10.1016/j.jhydrol.2016.07.041, URL https://www.sciencedirect. com/science/article/pii/S0022169416304711.

Moore, B.J., White, A.B., Gottas, D.J., Neiman, P.J., 2020. Extreme precipitation events in northern california during winter 2016-17: Multiscale analysis and climatological perspective. Mon. Weather Rev. 148 (3), 1049-1074. http://dx.doi.org/ 10.1175/MWR-D-19-0242.1, URL http://journals.ametsoc.org/doi/10.1175/MWRD-19-0242.1.

Münnich, M., Neelin, J.D., 2005. Seasonal influence of ENSO on the Atlantic ITCZ and equatorial South America. Geophys. Res. Lett. 32 (21), L21709. http://dx.doi.org/ 10.1029/2005GL023900, URL http://doi.wiley.com/10.1029/2005GL023900.

O'Gorman, P.A., 2015. Precipitation extremes under climate change. Curr. Clim. Chang. Rep. 1, 49-59. http://dx.doi.org/10.1007/s40641-015-0009-3.

O'Neill, B.C., et al., 2016. The scenario model intercomparison project (ScenarioMIP) for CMIP6. Geosci. Model Dev. 9 (9), 3461-3482. http://dx.doi.org/10.5194/gmd9-3461-2016, URL https://gmd.copernicus.org/articles/9/3461/2016/.

Oppel, H., Fischer, S., 2020. A new unsupervised learning method to assess clusters of temporal distribution of rainfall and their coherence with flood types. Water Resour. Res. 56 (5), http://dx.doi.org/10.1029/2019WR026511, URL https: //onlinelibrary.wiley.com/doi/10.1029/2019WR026511.

Pfahl, S., Madonna, E., Boettcher, M., Joos, H., Wernli, H., 2014. Warm conveyor belts in the ERA-interim dataset (1979-2010). Part II: Moisture origin and relevance for precipitation. J. Clim. 27 (1), 27-40. http://dx.doi.org/10.1175/Jcli-D-13-00223.1, URL https://journals.ametsoc.org/view/journals/clim/27/1/jcli-d-13-00223.1.xml.

Pfahl, S., O'Gorman, P.A., Fischer, E.M., 2017. Understanding the regional pattern of projected future changes in extreme precipitation. Nature Clim. Change 7 (6), 423-427. http://dx.doi.org/10.1038/nclimate3287, URL http://www.nature.com/ articles/nclimate 3287.

Pfahl, S., Wernli, H., 2012. Quantifying the relevance of cyclones for precipitation extremes. J. Clim. 25 (19), 6770-6780. http://dx.doi.org/10.1175/JCLI-D-1100705.1, URL http://journals.ametsoc.org/doi/10.1175/JCLI-D-11-00705.1.

Pinto, J.G., Bellenbaum, N., Karremann, M.K., Della-Marta, P.M., 2013. Serial clustering of extratropical cyclones over the North Atlantic and Europe under recent and future climate conditions. J. Geophys. Res.: Atmos. 118 (22), 12,47612,485. http://dx.doi.org/10.1002/2013JD020564, URL http://doi.wiley.com/10. 1002/2013JD020564.

Pinto, J.G., Gómara, I., Masato, G., Dacre, H.F., Woollings, T., Caballero, R., 2014. Large-scale dynamics associated with clustering of extratropical cyclones affecting Western Europe. J. Geophys. Res.: Atmos. 119 (24), 13,704-13,719. http://dx.doi. org/10.1002/2014JD022305, URL http://doi.wiley.com/10.1002/2014JD022305.
Priestley, M.D.K., Pinto, J.G., Dacre, H.F., Shaffrey, L.C., 2017a. Rossby wave breaking, the upper level jet, and serial clustering of extratropical cyclones in western Europe. Geophys. Res. Lett. 44 (1), 514-521. http://dx.doi.org/10.1002/2016GL071277, URL http://doi.wiley.com/10.1002/2016GL071277.

Priestley, M.D.K., Pinto, J.G., Dacre, H.F., Shaffrey, L.C., 2017b. The role of cyclone clustering during the stormy winter of 2013/2014. Weather 72 (7), 187-192. http: //dx.doi.org/10.1002/wea.3025, URL http://doi.wiley.com/10.1002/wea.3025.

Ratan, R., Venugopal, V., 2013. Wet and dry spell characteristics of global tropical rainfall. Water Resour. Res. 49 (6), 3830-3841. http://dx.doi.org/10.1002/wrcr. 20275, URL http://doi.wiley.com/10.1002/wrcr.20275.

Ripley, B.D., 1981. Spatial Statistics. In: Wiley Series in Probability and Statistics, John Wiley \& Sons, Inc., Hoboken, NJ, USA, http://dx.doi.org/10.1002/0471725218, URL http://doi.wiley.com/10.1002/0471725218.

Rivoire, P., Martius, O., Naveau, P., 2021. A comparison of moderate and extreme ERA-5 daily precipitation with two observational data sets. Earth Space Sci. 8 (4), e2020EA001633. http://dx.doi.org/10.1029/2020EA001633, URL https://agupubs. onlinelibrary.wiley.com/doi/full/10.1029/2020EA001633.

Roca, R., Bouniol, D., Fiolleau, T., 2020. On the Duration and Life Cycle of Precipitation Systems in the Tropics. pp. 729-744. http://dx.doi.org/10.1007/978-3-030-357986_14, URL http://link.springer.com/10.1007/978-3-030-35798-6_14.

Sillmann, J., Kharin, V.V., Zhang, X., Zwiers, F.W., Bronaugh, D., 2013. Climate extremes indices in the CMIP5 multimodel ensemble: Part 1. Model evaluation in the present climate. J. Geophys. Res.: Atmos. 118 (4), 1716-1733. http://dx.doi. org/10.1002/jgrd.50203, URL https://agupubs.onlinelibrary.wiley.com/doi/abs/10. 1002/jgrd.50203.

Tuel, A., Martius, O., 2021. A climatology of sub-seasonal temporal clustering of extreme precipitation in Switzerland and its impacts. Nat. Hazards Earth Syst. Sci. Discuss. [Preprint]. http://dx.doi.org/10.5194/nhess-2021-93.

Villarini, G., Smith, J.A., Baeck, M.L., Vitolo, R., Stephenson, D.B., Krajewski, W.F., 2011. On the frequency of heavy rainfall for the Midwest of the United States. J. Hydrol. 400 (1-2), 103-120. http://dx.doi.org/10.1016/j.jhydrol.2011.01.027, URL https://linkinghub.elsevier.com/retrieve/pii/S0022169411000527.

Vitolo, R., Stephenson, D.B., Cook, I.M., Mitchell-Wallace, K., 2009. Serial clustering of intense European storms. Meteorol. Z. 18 (4), 411-424. http://dx.doi.org/10.1127/ 0941-2948/2009/0393, URL http://www.schweizerbart.de/papers/metz/detail/18/ 73402/Serial_clustering_of_intense_European_storms?af=crossref.

Westra, S., Alexander, L.V., Zwiers, F.W., 2013. Global increasing trends in annual maximum daily precipitation. J. Clim. 26 (11), 3904-3918. http://dx.doi.org/10.1175/ JCLI-D-12-00502.1, URL https://journals.ametsoc.org/view/journals/clim/26/11/ jcli-d-12-00502.1.xml.

Wilks, D.S., 2016. "The stippling shows statistically significant grid points": How research results are routinely overstated and overinterpreted, and what to do about it. Bull. Am. Meteorol. Soc. 97 (12), 2263-2273. http://dx.doi.org/10. 1175/BAMS-D-15-00267.1, URL https://journals.ametsoc.org/view/journals/bams/ 97/12/bams-d-15-00267.1.xml.

Xie, P., Joyce, R., Wu, S., Yoo, S.-H., Yarosh, Y., Sun, F., Lin, R., 2017. Reprocessed, bias-corrected CMORPH global high-resolution precipitation estimates from 1998. J. Hydrometeorol. 18 (6), 1617-1641. http://dx.doi.org/10.1175/JHM-D-16-0168.1, URL http://journals.ametsoc.org/doi/10.1175/JHM-D-16-0168.1.

Yang, Z., Villarini, G., 2019. Examining the capability of reanalyses in capturing the temporal clustering of heavy precipitation across Europe. Clim. Dynam. 53 (34), 1845-1857. http://dx.doi.org/10.1007/s00382-019-04742-z, URL http://link. springer.com/10.1007/s00382-019-04742-z.

Zscheischler, J., et al., 2020. A typology of compound weather and climate events. Nat. Rev. Earth Environ. 1 (7), 333-347. http://dx.doi.org/10.1038/s43017-020-0060-z, URL http://www.nature.com/articles/s43017-020-0060-z. 